\title{
Input-Specific Modulation of Neurotransmitter Release in the Lateral Horn of the Spinal Cord via Adenosine Receptors
}

\author{
Ruth E. Brooke, Jim Deuchars, and Susan A. Deuchars \\ School of Biomedical Sciences, University of Leeds, Leeds LS2 9NQ, United Kingdom
}

Activation of adenosine $\mathrm{A} 2{ }_{\mathrm{A}}$ receptors $\left(\mathrm{A} 2_{\mathrm{A}} \mathrm{Rs}\right)$ in the CNS produces a variety of neuromodulatory actions dependent on the region and preparation examined. In autonomic regions of the spinal cord, A1R activation decreases excitatory synaptic transmission, but the effects of $\mathrm{A} 2{ }_{\mathrm{A}} \mathrm{R}$ stimulation are unknown. We sought to determine the location and function of the $\mathrm{A} 2_{\mathrm{A}} \mathrm{Rs}$ in the thoracic spinal cord, focusing on the intermediolateral cell column (IML). $\mathrm{A} 2_{\mathrm{A}} \mathrm{R}$ immunoreactivity was observed throughout the gray matter, with particularly dense immunostaining in regions containing sympathetic preganglionic neurons (SPNs), namely, the IML and intercalated nucleus. Electron microscopy revealed $\mathrm{A} 2{ }_{\mathrm{A}} \mathrm{R}$ immunoreactivity within presynaptic terminals and in postsynaptic structures in the IML. To study the functional relevance of these $\mathrm{A} 2_{\mathrm{A}} \mathrm{Rs}$, visualized whole-cell patch-clamp recordings were made from electrophysiologically identified SPNs and interneurons within the IML. The $\mathrm{A} 2{ }_{\mathrm{A}} \mathrm{R}$ agonist $\mathrm{c} 2$-[ $p$-(carboxyethyl)phenethylamino]-5'- $N$-ethylcarboxyamidoadenosine (CGS 21680) had no significant effect on EPSPs but increased the amplitude of IPSPs elicited by stimulation of the lateral funiculus. These effects were attributable to activation of presynaptic $\mathrm{A} 2{ }_{\mathrm{A}} \mathrm{Rs}$ because CGS 21680 application altered the paired pulse ratio. Furthermore, neurons in the IML that have IPSPs increased via $\mathrm{A} 2{ }_{\mathrm{A}} \mathrm{R}$ activation also receive excitatory inputs that are inhibited by $\mathrm{A} 1 \mathrm{R}$ activation. These data show that activating $\mathrm{A} 2{ }_{\mathrm{A}} \mathrm{Rs}$ increase inhibitory but not excitatory transmission onto neurons in the IML. Simultaneous activation of $\mathrm{A} 1 \mathrm{Rs}$ and $\mathrm{A}{ }_{\mathrm{A}} \mathrm{Rs}$ therefore could facilitate inhibition of the postsynaptic neuron, leading to an overall reduction of sympathetic nervous activity.

Key words: adenosine; autonomic; immunoreactivity; patch clamp; spinal; sympathetic

\section{Introduction}

The important neuromodulatory actions of adenosine are mediated via G-protein-coupled receptors classified as A1-A3. Adenosine $\mathrm{A} 2$ receptors (A2Rs) are further divided into high- and low-affinity $\mathrm{A} 2{ }_{\mathrm{A}}$ and $\mathrm{A} 2{ }_{\mathrm{B}}$ receptor subtypes, respectively (Daly et al., 1983). Adenosine acting on presynaptic and postsynaptic A2Rs elicits predominantly excitatory effects via activation of G-proteins that stimulate adenylate cyclase activity (Daly et al., 1983). The facilitatory effects of $\mathrm{A} 2{ }_{\mathrm{A}} \mathrm{R}$ activation are well known in excitatory synaptic transmission (for review, see Sebastiao and Ribeiro, 1996), but the regulation of inhibitory transmission is less well defined. $\mathrm{A} 2{ }_{\mathrm{A}} \mathrm{R}$ activation enhanced electrically stimulated GABA release in striatal slices (Mayfield et al., 1993) and increased GABA-mediated IPSCs in globus pallidus slices (Shindou et al., 2001, 2002). In addition, $\mathrm{A} 2{ }_{\mathrm{A}} \mathrm{R}$ activation increased GABA release from hippocampal synaptosomes (Cunha and Ribeiro, 2000). Conversely, $\mathrm{A} 2_{\mathrm{A}}$-mediated decreases in GABA release were observed in striatal synaptosomes (Kirk and Richardson, 1995) and synaptosomal preparations of the caudateputamen and globus pallidus (Kurokawa et al., 1994). Moreover,

Received June 19, 2003; revised Nov. 7, 2003; accepted Nov. 11, 2003.

This work was supported by British Heart Foundation Grant PG/2001119 and The Wellcome Trust. We thank Brenda Frater for expert technical help.

Correspondence should be addressed to Susan A. Deuchars, School of Biomedical Sciences, University of Leeds, Worsley Building, Leeds, LS2 9NQ, UK. E-mail: s.a.deuchars@leeds.ac.uk.

DOI:10.1523/JNEUROSCI.4591-03.2004

Copyright $\odot 2004$ Society for Neuroscience $\quad$ 0270-6474/04/240127-11\$15.00/0 using intracellular and whole-cell patch-clamp techniques in rat striatal slices, a decrease in GABAergic IPSPs in striatal medium spiny neurons has been demonstrated (Mori et al., 1996). Thus, the role of $\mathrm{A} 2{ }_{\mathrm{A}} \mathrm{Rs}$ in GABAergic neurotransmission apparently varies considerably. The only report of A2R modulation of glycine release was in the brainstem, but this could have been attributable to $\mathrm{A} 2{ }_{\mathrm{B}} \mathrm{R}$ activation (Umemiya and Berger, 1994).

$\mathrm{A} 2{ }_{\mathrm{A}} \mathrm{Rs}$ have been shown to influence autonomic homeostatic mechanisms through a neuromodulatory role in several brainstem nuclei (Barraco et al., 1993). However, little is known of the possible involvement of $\mathrm{A} 2{ }_{\mathrm{A}} \mathrm{Rs}$ in autonomic regulation at the spinal level. Neither in situ hybridization (Kaelin-Lang et al., 1999) nor autoradiography (Choca et al., 1987, 1988) reported $\mathrm{A} 2{ }_{\mathrm{A}} \mathrm{R}$ in regions containing sympathetic preganglionic neurons (SPNs), the final common pathway for sympathetic activity and source of spinal autonomic outflow. Nevertheless, spinal $\mathrm{A} 2{ }_{\mathrm{A}} \mathrm{Rs}$ appear to influence sympathetic outflow because intrathecal administration of an $\mathrm{A} 2 \mathrm{R}$ agonist at the thoracic spinal cord level decreased blood pressure and heart rate, consistent with a reduction in sympathetic activity (Koh et al., 2000). This was somewhat surprising because intrathecal administration of A1R agonists caused similar cardiovascular effects (Koh et al., 1996). In a previous study, we revealed that the A1R-mediated effects on sympathetic outflow could be attributable to reduction in activity in SPNs because activation of A1Rs in the lateral horn of the spinal cord decreased excitatory transmitter release onto SPNs and interneurons without effects on inhibitory transmission (Deuchars 
et al., 2001b). Considering the diversity of responses observed as a result of activation of $\mathrm{A} 2{ }_{\mathrm{A}} \mathrm{Rs}$ at a cellular level, we were prompted to investigate how $\mathrm{A} 2{ }_{\mathrm{A}} \mathrm{Rs}$ may exert an influence on sympathetic nervous activity.

Thus we studied the distribution of the $\mathrm{A} 2{ }_{\mathrm{A}} \mathrm{R}$ in the thoracic spinal cord at the light and electron microscopic level using immunohistochemistry. When these studies revealed dense $A 2{ }_{A} R$ immunoreactivity in the intermediolateral cell column (IML), electrophysiological experiments investigated the role of these $\mathrm{A} 2{ }_{\mathrm{A}} \mathrm{Rs}$ in modulating neuronal activity in the IML.

\section{Materials and Methods}

All experiments were performed under a United Kingdom Home Office license and in accordance with the regulations of the United Kingdom Animals (Scientific Procedures) Act of 1986. Efforts were made to minimize animal suffering and to use only the minimum number of animals required.

Western blot analysis. The primary antibody was raised in goat against a peptide mapping near the intracellular $\mathrm{C}$ terminus of the rat $\mathrm{A} 2_{\mathrm{A}}$ receptor (anti-A2 ${ }_{\mathrm{A}} \mathrm{R}$; Santa Cruz Biotechnology, Santa Cruz, CA). Specificity was determined by Western blot analysis. Rat brainstem and spinal cord were separately isolated and crushed under liquid nitrogen. Tissue was resuspended in homogenization buffer [500 $\mu$ l of protease inhibitor (1 mM iodoacetamide, $1 \mathrm{~mm}$ benzathonium chloride, and 5.7 mM PMSF in $5 \mathrm{ml}$ of $1 \%$ SDS), $10 \mathrm{~mm}$ EDTA, and $300 \mathrm{~mm}$ sucrose in $4.5 \mathrm{ml}$ of $1 \%$ SDS] and centrifuged at 10,000 rpm for 3-4 min until a clear pellet and supernatant could be defined. Tissue proteins $(30 \mu \mathrm{g})$ were separated by SDSPAGE using $10 \%$ acrylamide gels in a Bio-Rad (Hercules, CA) cell electrophoresis tank and power pack for $2 \mathrm{hr}$ at $40 \mathrm{~mA} / \mathrm{gel}$. After separation, proteins were transferred to a nitrocellulose membrane by semidry blotting for $1.5 \mathrm{hr}$ at $50 \mathrm{~mA} / \mathrm{gel}$. Nonspecific binding sites were blocked by immersing the membrane in PBS (in mM: $5 \mathrm{KH}_{2} \mathrm{PO}_{4}, 5 \mathrm{Na}_{2} \mathrm{HPO}_{4}$, and $130 \mathrm{NaCl}, \mathrm{pH} 7.2)$ containing $10 \%(\mathrm{w} / \mathrm{v})$ dried skim milk overnight at $4^{\circ} \mathrm{C}$. The membrane was washed three or four times with $0.05 \%$ Tween 20 in PBS. Membranes were probed with anti- $\mathrm{A} 2{ }_{\mathrm{A}} \mathrm{R}$ primary antibody $(0.1 \mu \mathrm{g} / \mathrm{ml})$ for $1 \mathrm{hr}$ at room temperature while being agitated and then washed three times with PBS and Tween 20. Bound antibody was detected by anti-goat Ig conjugated to horseradish peroxidase (1:3000; Dako, High Wycombe, UK). Immunoreactivity was visualized by using a peroxidase-based chemiluminescent substrate kit (Amersham Biosciences, Buckinghamshire, UK).

Immunohistochemistry. Male rats $(150-200 \mathrm{gm} ; n=10)$ were deeply anesthetized by intraperitoneal Sagatal $(60 \mathrm{mg} / \mathrm{kg})$ and transcardially perfused with fixative containing $4 \%$ paraformaldehyde and $0.1-0.5 \%$ glutaraldehyde in $0.1 \mathrm{~m}$ phosphate buffer $(\mathrm{PB}) \mathrm{pH}$ 7.4. Spinal cords were removed at the thoracic level and postfixed in perfusing fixative for $4 \mathrm{hr}$. At the level of T2-T5, a $5 \mathrm{~mm}$ section of the spinal cord was cut, sectioned further at $50 \mu \mathrm{m}$ on a vibrating microtome (Leica, Nussloch, Germany), and collected into PBS, pH 7.2. Forebrain sections containing the striatum were also prepared as a positive control. For electron microscopy, sections were cryoprotected by incubation in $10 \%$ sucrose in $0.1 \mathrm{M}$ PB for $10 \mathrm{~min}$ followed by $20 \%$ sucrose in $0.1 \mathrm{M} \mathrm{PB}$ for $20 \mathrm{~min}$ and then freezethawed twice in liquid nitrogen to permeabilize the membranes. For light microscopy, the tissue was permeabilized using $0.1 \%$ Triton X-100 included with the primary antibody solution.

Sections were immersed in primary antibody diluted 1:200-1:800 in PBS for $12-48 \mathrm{hr}$ at $4^{\circ} \mathrm{C}$. For further controls, sections were incubated with PBS in place of primary antiserum or with the goat primary antiserum that had been preabsorbed with the peptide antigen for $1 \mathrm{hr}$ before use ( $1 \mu \mathrm{g}$ of peptide for $1 \mu \mathrm{g}$ of antibody).

For light and electron microscopy, sections were washed three times for $10 \mathrm{~min}$ in PBS and placed into a biotinylated secondary antibody to goat IgG (1:200 in PBS; Vector Laboratories, Burlingame, CA). After 5 hr at $4^{\circ} \mathrm{C}$, the sections were washed three times for $10 \mathrm{~min}$ in PBS and put into ExtraAvidin peroxidase (1:1500; Sigma, St. Louis, MO) for 18-20 hr at $4^{\circ} \mathrm{C}$. These sections were then washed in Tris- $\mathrm{HCl}$ buffer, $\mathrm{pH} 7.4$, and incubated in diaminobenzidine (DAB; Sigma) solution $(5 \mathrm{mg}$ in $10 \mathrm{ml}$ of Tris buffer with $0.01 \% \mathrm{H}_{2} \mathrm{O}_{2}$ ) for $10 \mathrm{~min}$. Some sections were mounted on gelatin-coated slides for light microscopy only. Other sections were washed in $0.1 \mathrm{M} \mathrm{PB}$ for $10 \mathrm{~min}$ and postfixed in $0.5 \%$ osmium tetroxide (in $0.1 \mathrm{M} \mathrm{PB}$ ) for $45 \mathrm{~min}$. After washing three times for $10 \mathrm{~min}$ in $0.1 \mathrm{M} \mathrm{PB}$, the sections were dehydrated through an ethanol series followed by two 10 min washes in propylene oxide (Fisher Scientific, Pittsburgh, PA). The sections were then immersed in Durcupan ACM resin (Fluka, Buchs, Switzerland) for 12-20 hr, mounted on glass slides, and placed in an oven at $60^{\circ} \mathrm{C}$ for $48 \mathrm{hr}$ to polymerize the resin. Slides were subsequently examined at the light microscope level, and images were obtained via an integrating analog CCD camera (JVC KYF 55B) attached to an Acquis image capture system (Synoptics) and adjusted for brightness, contrast, intensity, and color balance using CorelDraw 10 before printing. Electron microscopy was then conducted as described in detail elsewhere (Deuchars et al., 2001a,b).

For fluorescent microscopy, sections were incubated in goat primary antibody and then for $4 \mathrm{hr}$ in Cy3-conjugated donkey anti-goat IgG (1:1000; Jackson ImmunoResearch, West Grove, PA). Sections were dried on gelatinized slides at $4^{\circ} \mathrm{C}$, covered with Vectamount (Vector Laboratories), and stored at $4^{\circ} \mathrm{C}$. Cy3 was visualized with a custom Cy3 filter set, and digital images were acquired as above.

Specificity of antibody. Several lines of evidence converged to indicate that the primary antibody specifically detected the $\mathrm{A} 2{ }_{\mathrm{A}}$ receptor: (1) The antibody has previously been verified as detecting the $\mathrm{A} 2{ }_{\mathrm{A}}$ receptor in striatum and hippocampal nerve terminals (Rebola et al., 2002). (2) The antibody recognizes a protein with a molecular weight appropriate for the $\mathrm{A} 2_{\mathrm{A}}$ receptor because Western blotting of rat spinal cord resulted in a predominant band at $45 \mathrm{kDa}$ with another minor band at $62 \mathrm{kDa}$ (Fig. $1 \mathrm{~A}$ ). The $45 \mathrm{kDa}$ band corresponds to the predicted molecular weight of the $\mathrm{A} 2{ }_{\mathrm{A}}$ receptor and has been observed in CNS and other tissue using antisera to different epitopes of the $\mathrm{A} 2{ }_{\mathrm{A}}$ receptor (Rosin et al., 1998; Lynge and Hellsten, 2000). The $62 \mathrm{kDa}$ band has also been detected with other anti-A2 ${ }_{\mathrm{A}}$ antibodies (Lynge and Hellsten, 2000) and may be attributable to glycosylation of the receptor. (3) There was no staining when the primary antiserum was preadsorbed with the antigenic peptide (Fig. $1 A$ ), indicating that the antibodies bind to the appropriate sequence of the $\mathrm{A} 2 \mathrm{~A}$ receptor. (4) This specificity is retained in tissue sections because no staining was observed in control sections in which the primary antibody was preadsorbed against the control peptide (Fig. 1A,C), which indicates that the antibody recognized the appropriate sequence in the tissue. (5) The staining was attributable to the primary antibody because omission of the primary antibody resulted in no staining (results not shown). (6) As a positive control, immunostaining in other regions of the CNS (striatum; Fig. $1 B$ ) was consistent with previous reports of $\mathrm{A}_{2} \mathrm{~A}$ receptor localization in these brain regions using autoradiography (Jarvis and Williams, 1989; Parkinson and Fredholm, 1990). (7) The staining observed in the dorsal and ventral horns of the spinal cord (see below) was consistent with localization of $\mathrm{A} 2 \mathrm{~A}$ receptor-binding sites (Choca et al., 1987, 1988).

Retrograde labeling of SPNs and immunohistochemistry. To retrogradely label the complete population of SPNs, male rats ( $150 \mathrm{gm} ; n=3$ ) were injected intraperitoneally with $0.1 \mathrm{ml}$ of $1 \%$ Fluorogold (Fluorochrome Inc.) $7 \mathrm{~d}$ before immunohistochemistry (Ambalavanar and Morris, 1989; Anderson and Edwards, 1994). After 7 d, the rats were deeply anesthetized with pentobarbitone sodium $(60 \mathrm{mg} / \mathrm{kg}$, i.p.) and perfused transcardially with $0.9 \% \mathrm{NaCl}$ followed by fixative containing $4 \%$ paraformaldehyde. Sections were washed in PBS, and the $\mathrm{A} 2{ }_{\mathrm{A}} \mathrm{R}$ immunostaining was performed for fluorescent detection as described above. Fluorogold was visualized with UV illumination and immunostaining with a custom Cy3 filter set.

Electrophysiology. Rats aged 10-15 d were anesthetized with urethane ( $2 \mathrm{gm} / \mathrm{kg}$, i.p.). The thoracic spinal cord was exposed, and the dorsal and ventral roots were cut to isolate the cord. The upper and middle thoracic portions of the spinal cord were removed and submerged in ice-cold sucrose artificial CSF (aCSF) containing (in $\mathrm{mm}$ ): 217 sucrose, 26 $\mathrm{NaHCO}_{3}, 3 \mathrm{KCl}, 2 \mathrm{MgSO}_{4}, 2.5 \mathrm{NaH}_{2} \mathrm{PO}_{4}, 1 \mathrm{CaCl}_{2}$, and 10 glucose and equilibrated with $95 \% \mathrm{O}_{2}$ and $5 \% \mathrm{CO}_{2}$. The dorsal and ventral roots were cut, and the dura mater was removed. The pia mater was carefully teased away from the spinal cord, and the clean spinal cord was immersed in warm agar that was placed on ice for rapid setting. Slices ( $250 \mu \mathrm{m}$ thick) 

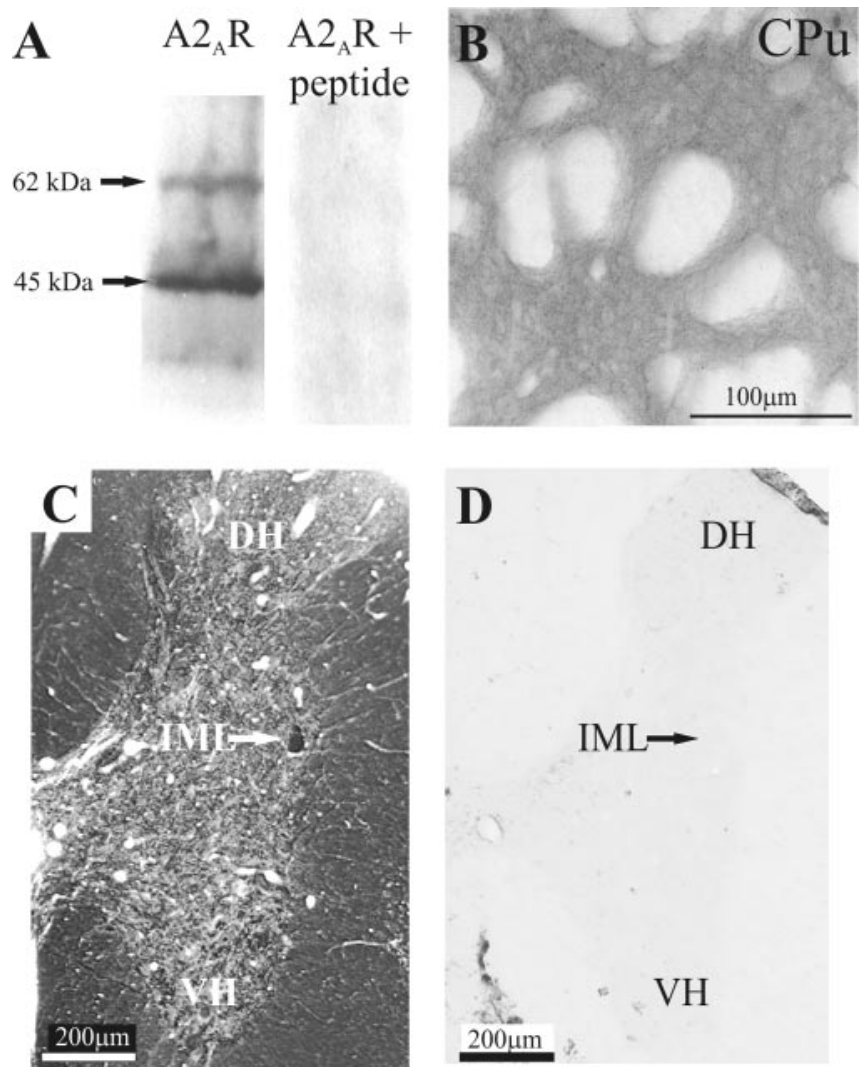

Figure 1. Specificity of $A 2_{A} R$ primary antibody. $A$, Western blotting of rat thoracic spinal cord resulted in staining of a major band running at $\sim 45 \mathrm{kDa}$ and a minor band of $\sim 62 \mathrm{kDa}$ when detected with the anti- $\mathrm{AZ}_{A}$ receptor antibody. No staining of the membrane was obtained after preabsorption of the antiserum with the cognate peptide. $B$, Low magnification of $A 2_{A} R$ immunoreactivity in the striatum. In accordance with previous reports, dense immunolabeling for the $A 2_{A} R$ can be seen in the neuropil in the striatum. $C P u$, Caudate-putamen. $C, A 2_{A} R$ immunoreactivity in the thoracic spinal cord visualized with DAB. Dense staining can be seen in the IML (arrow). D, No staining was observed after preincubation of the primary antibody with the immunogenic peptide. DH, Dorsal horn; $\mathrm{VH}$, ventral horn.

of the embedded spinal cord were cut on a Vibroslice and placed into the recording chamber or a holding chamber for later use. The slices were submerged in aCSF (in mM: $124 \mathrm{NaCl}, 26 \mathrm{NaHCO}_{3}, 3 \mathrm{KCl}, 2 \mathrm{MgSO}_{4}, 2.5$ $\mathrm{NaH}_{2} \mathrm{PO}_{4}, 2 \mathrm{CaCl}_{2}$, and 10 glucose), equilibrated with $95 \% \mathrm{O}_{2}$ and $5 \% \mathrm{CO}_{2}$, and superfused at a rate of $3-5 \mathrm{ml} / \mathrm{min}$. All experiments were performed at room temperature. Visualized patch-clamp recording setups were used with an upright microscope (Eclipse E600FN; Nikon, Melville, NY; or BX50WI; Olympus Optical, Tokyo, Japan). The IML was located at $10 \times$ magnification, and the cells were visualized at $60 \times$ magnification for recording. Both SPNs and interneurons within and around the IML were targeted for these experiments, identified both electrophysiologically and anatomically (see below).

Whole-cell patch-clamp recordings were obtained from neurons after achieving tight $(>5 \mathrm{G} \Omega$ ) resistance seals. Recordings were made in currentclamp mode using an Axopatch 1D (Axon Instruments). Patch electrodes (tip diameter, $3 \mu \mathrm{m}$; resistance, $4-6 \mathrm{M} \Omega$ ) were filled with (in $\mathrm{mm}$ ): 110 K-gluconate, 11 EGTA, $2 \mathrm{MgCl}_{2}, 1 \mathrm{CaCl}_{2}, 10 \mathrm{HEPES}, 5 \mathrm{Na}_{2} \mathrm{ATP}$, and 0.3 $\mathrm{Na}_{2}$ GTP, pH 7.2, $295 \mathrm{mOsm}$. Neurobiotin (0.5\%) was included in the patch solution and diffused into the neuron during recording.

Neurons were first characterized by applying hyperpolarizing and depolarizing current pulses (1 sec duration). Hyperpolarizing current pulses $(-10$ to $-150 \mathrm{pA})$ produced voltage responses that were characteristically different for the types of neurons studied. The input resistance of the neuron could also be calculated from the response to a hyperpolarizing current pulse. Depolarizing current pulses brought the neurons to the threshold for firing, and the shapes of the action potentials were examined to further differentiate the neurons.
The lateral funiculus (lf) contains descending fibers originating in areas of the brainstem involved in sympathetic control and was stimulated using a bipolar stimulating electrode placed just below the surface of the slice. The If was stimulated above the threshold for response but ensuring that the response was submaximal, using an isolated stimulator (Digitimer DS2A). Single-pulse stimulation was used, except for the series of experiments looking at paired pulse ratios, in which a second stimulus was applied 100-300 msec after the first. The response in control solution was always an EPSP, but an IPSP could also be obtained at more depolarized potentials using the same stimulation parameters either in control conditions or by blocking the EPSP with selective antagonists. The input resistance of the neuron was also tested just before, during, and after application of drugs. To examine IPSPs, the neurons were held at a membrane potential of -10 to $-20 \mathrm{mV}$, and for EPSPs, they were held at -60 to $-70 \mathrm{mV}$.

Drugs were applied in the superfusing solution at a rate of $3-5 \mathrm{ml} / \mathrm{min}$, and the concentration given is the final concentration in the bath. Drugs used were the $\mathrm{A} 2{ }_{\mathrm{A}} \mathrm{R}$ agonist $\mathrm{c} 2$-[ $p$-(carboxyethyl)phenethylamino] $-5^{\prime}-\mathrm{N}$ ethylcarboxyamidoadenosine [CGS 21680, dissolved in dimethylsulfoxide (DMSO)], the $\mathrm{A} 2{ }_{\mathrm{A}} \mathrm{R}$ antagonist 4-(2-[-7-amino-2-(2-furyl)[1,2,4] triazolo[2,3-a]-[1,3,5]triazin-5-ylamino] ethyl)phenol (ZM 241385, dissolved in DMSO), the A1R agonist cyclopentyladenosine (CPA; Sigma), and the A1R antagonist 8-cyclopentyl-1,3-dimethylxanthine (CPT, dissolved in $0.1 \mathrm{~N} \mathrm{NaOH}$; Sigma). To uncover IPSPs, the excitatory amino acid antagonists 1,2,3,4-tetrahydro-6-nitro-2,3-dioxobenzo[f] quinoxaline-7sulfonamide disodium (NBQX) and $\mathrm{D}(-)$-2-amino-5-phosphopentanoic acid (AP-5) were applied. Bicuculline and strychnine (Sigma) were used to block the IPSPs. All drugs were obtained from Tocris and dissolved in water unless otherwise stated.

Data analysis. The voltage responses to current pulses were examined to reveal the presence of any currents specific to either type of neuron. The action potential duration, amplitude, and afterhyperpolarization (AHP) were measured for each neuron because interneurons display action potentials of significantly shorter duration and have smaller AHPs (Deuchars et al., 2001a).

The EPSP and IPSP amplitudes were measured as the peak changes from the holding potentials, averaged over 10 consecutive sweeps for control and drug responses, and given as the mean \pm SEM. The effects of the drugs were tested statistically using the paired Student's $t$ test, and differences were considered significant at $p<0.05$. Any effects of the drugs on resting potential and input resistance were also noted. The responses of a neuron to paired pulse stimulation of the lf were given as the ratio of the second response to the first response. Paired pulse ratios were then calculated in control medium and in CGS 21680 and compared to determine whether there was a significant change. A change in paired pulse ratio is indicative of a presynaptic site of action probably attributable to differences in the numbers of synaptic vesicles available for release with the second stimulus, the intracellular calcium concentration, or both. For example, if presynaptic receptors are activated that increase the amount of neurotransmitter released in response to the first stimulus, fewer vesicles will be available for the second stimulus and the amplitude of the second EPSP or IPSP will be smaller, reducing the paired pulse ratio. The opposite will occur with an agonist that decreases the amount of neurotransmitter released in response to the first stimulus.

\section{Results}

\section{Immunohistochemistry}

Light microscopy

$\mathrm{A} 2{ }_{\mathrm{A}} \mathrm{R}$ immunoreactivity $\left(\mathrm{A} 2{ }_{\mathrm{A}} \mathrm{R}-\mathrm{IR}\right)$ was seen throughout the spinal cord, but the relative density of the staining varied between regions (Fig. $2 A$ ). In the ventral horn, strong staining was apparent in fibers and somata of presumptive motoneurons (Fig. 2E). A similar pattern of staining was observed in lamina I and II of the dorsal horn (Fig. 2D) and in the vicinity of the central canal (Fig. $2 F$ ), where fibers and neuronal somata were evident. Even at low magnifications, the IML was observed as a region containing dense staining (Fig. $2 B$ ). At higher magnification, the staining within the IML was evident as a compact region of punctate 
structures (Fig. 2C). When SPNs were retrogradely labeled by intraperitoneal injections of Fluorogold (Fig. $2 \mathrm{H}$ ) the A2 ${ }_{\mathrm{A}} \mathrm{R}-\mathrm{IR}$ was localized in the same region as the retrogradely labeled neurons (Fig. 2G). Occasionally, Fluorogold-positive SPNs also contained cytoplasmic $\mathrm{A} 2{ }_{\mathrm{A}} \mathrm{R}-\mathrm{IR}$; however, most of the $\mathrm{A} 2{ }_{\mathrm{A}} \mathrm{R}-\mathrm{IR}$ was punctate in nature.

To determine the identity of the punctate structures in the IML, we performed electron microscopy. This ultrastructural examination revealed $\mathrm{A} 2{ }_{\mathrm{A}} \mathrm{R}$-IR localized to both presynaptic and postsynaptic elements. Presynaptically, immunoreactivity was present in myelinated fibers in the lateral funiculus (Fig. $3 A$ ) and in presynaptic terminals (Fig. $3 B-D, F$ ) within the IML. The staining in terminals was limited and usually restricted to one region of the terminal, in common with that observed in immunolabeling for many other metabotropic receptors. Postsynaptically, staining was evident in dendrites, located at the postsynaptic density (Fig. 3E), or at nonsynaptic sites (Fig. $3 F$ ) as well as somata (results not shown). In somata, immunoreactivity was also associated with the endoplasmic reticulum (results not shown). Thus, ultrastructural examination revealed the punctate $\mathrm{A} 2{ }_{\mathrm{A}} \mathrm{R}-\mathrm{IR}$ structures observed at the light microscopic level to be discrete patches of immunoreactivity within neurons.

\section{Electrophysiology}

Electrophysiological characteristics of SPNs and interneurons in the IML

Because both SPNs and interneurons are located in the IML of the spinal cord and are thus both likely to be targets of $\mathrm{A} 2{ }_{\mathrm{A}} \mathrm{R}$ positive terminals in this region, electrophysiological studies were carried out on both these neuronal types. It was possible to distinguish between the two types of neurons due to their different electrophysiological and morphological characteristics. SPNs showed a delayed return to the holding potential at the end of a hyperpolarizing current pulse, indicative of activation of an $I_{\mathrm{A}}$ (Fig. $4 \mathrm{~A}$ ). In contrast, interneurons within the IML are characterized by a sag in the voltage response to a hyperpolarizing current pulse, suggesting activation of an $I_{\mathrm{H}}$ (Fig. 4B). In addition, interneuronal action potentials are significantly shorter in duration than those of SPNs (Fig. 4C) and have a complex but smaller afterhyperpolarization (Deuchars et al., 2001a). Because differentiation between SPNs and interneurons was easily determined electrophysiologically, the responses of both types of neurons to applications of $\mathrm{A} 2{ }_{\mathrm{A}} \mathrm{R}$ agonists and antagonists could be compared.
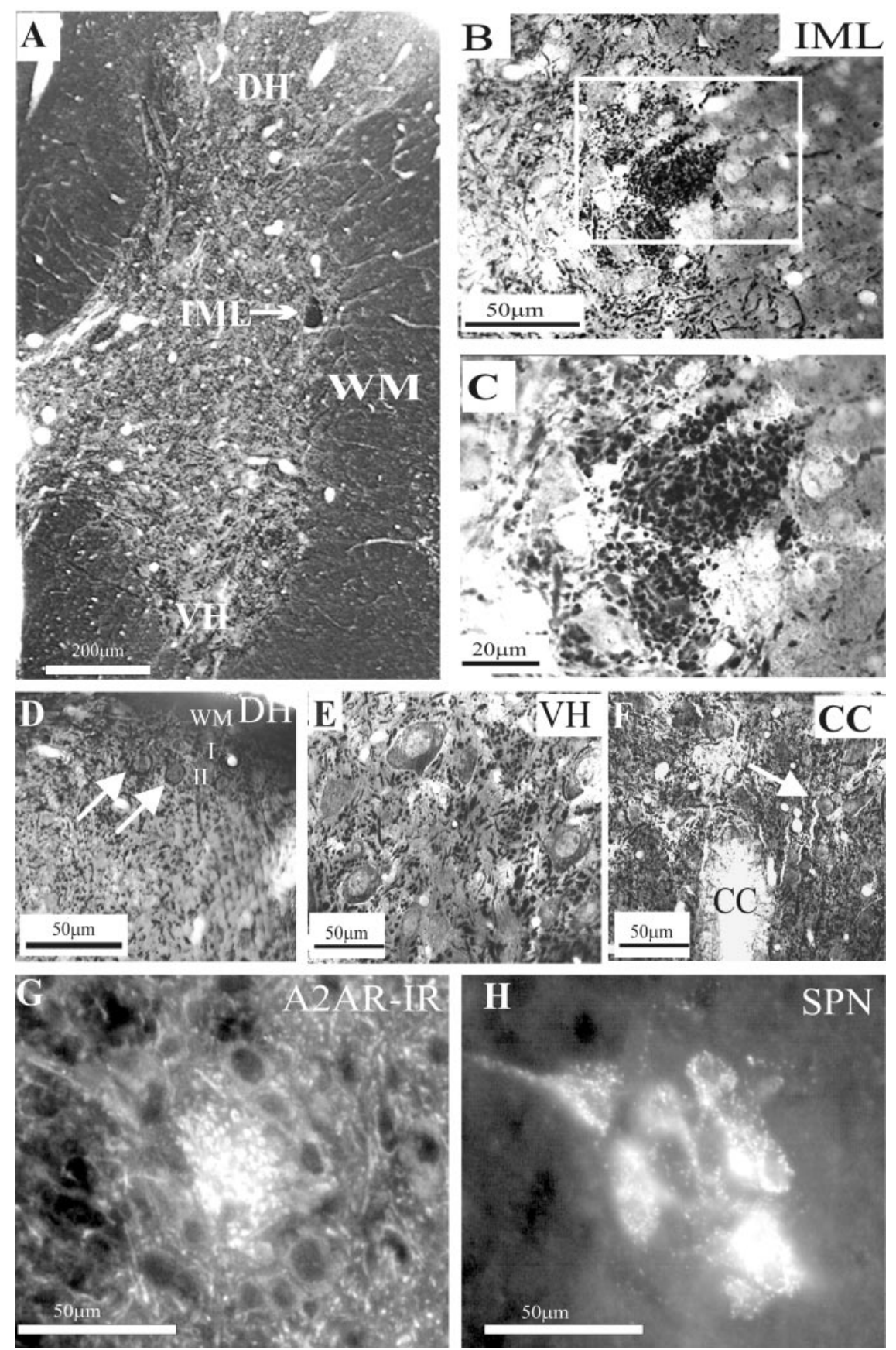

Figure 2. Adenosine $A 2_{A}$ receptor immunoreactivity in the thoracic spinal cord. $A$, Low magnification of $A 2_{A} R$ immunoreactivity visualized with $D A B$. Labeling was observed throughout the spinal cord. Even at low magnification, a compact region of dense staining is clearly seen in the IML. Staining is also evident in the dorsal horn (DH) and ventral horn (VH). B, Low magnification of the IML. A compact region of punctate staining was observed in the IML adjacent to the white matter (WM), distinguishing this area from the surrounding neuropil. C, High magnification of the boxed area in $B$. At higher magnification, the punctate structures are clearly identifiable. $D$, In the dorsal horn, staining of fibers was dense in the superficial lamina, and labeled neuronal somata were also observed in lamina II (arrows). I, Lamina I; II, lamina II. E, In the ventral horn-labeled fibers, somata and proximal dendrites of large neurons were observed. $F$, In the vicinity of the central canal, labeling was observed in somata (arrow) as well as in presumptive fibers. $G$, High magnification of $A 2_{A} R$ immunuoreactivity in the IML visualized with Cy3. A dense region of punctate staining can be observed in the IML. $H$, Sympathetic preganglionic neurons retrogradely labeled with Fluorogold in the same section as in $G$, viewed under UV illumination.
The $A 2_{A} R$ agonist CGS 21680 has no effect on EPSPs elicited by lf stimulation in both SPNs and interneurons.

The effects of applications of the $\mathrm{A} 2{ }_{\mathrm{A}} \mathrm{R}$ agonist CGS 21680 (25 nM and $1 \mu \mathrm{M})$ were determined on EPSPs elicited in both SPNs $(n=$ 31 ) and interneurons $(n=17)$ by stimulation of the lateral funic- 

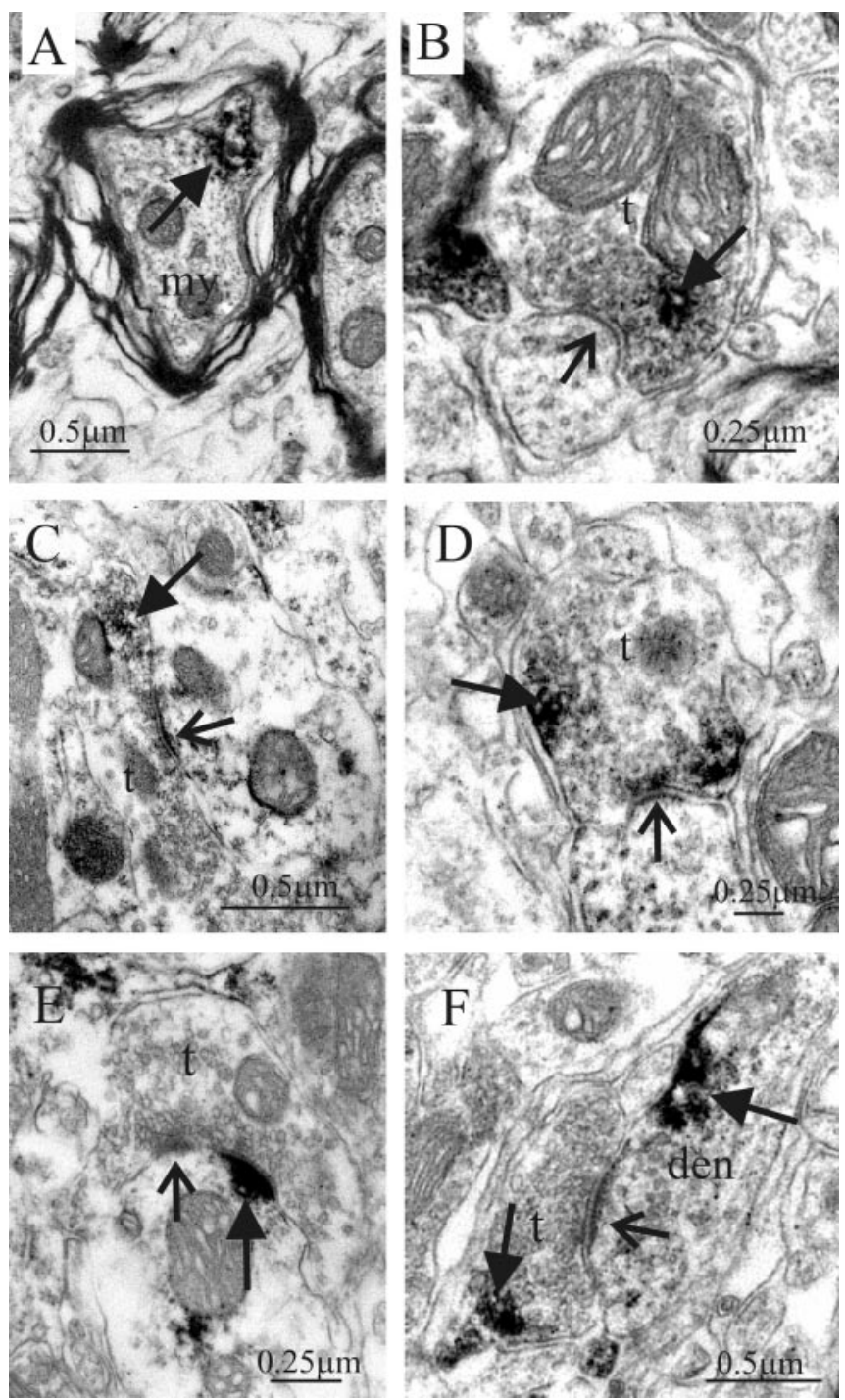

Figure 3. Electron microscopic localization of $A 2_{A} R$ immunoreactivity in the IML. $A, A 2_{A} R$ immunoreactivity (arrow) in a myelinated fiber (my) in the lateral funiculus. $B$, Presynaptic terminal $(t)$ in the IML containing immunoreactivity for the $A 2_{A} R$ (arrow, immunoreaction product). This terminal forms a synaptic contact (open arrow) with a dendritic structure. C, A large presynaptic terminal in the IML containing immunoreactivity (arrow) for the $A 2_{A} R$ forms a synaptic contact (open arrow) with a dendritic profile. $D, A 2_{A} R$-immunoreactive terminal in synaptic contact (open arrow) with a dendritic structure. $E, A 2_{A} R$ immunoreactivity (arrow) at the postsynaptic membrane of a synaptic junction (open arrow) where the presynaptic terminal is not labeled. $F$, Synaptic junction (open arrow) where both the presynaptic terminal and the postsynaptic dendritic (den) structure contained $\mathrm{A}_{\mathrm{A}} \mathrm{R}$ immunoreactivity (arrows).

ulus. The lf was chosen because this contains descending axons that make monosynaptic connections onto SPNs, whereas inputs from the dorsal horn are polysynaptic and thus more difficult to analyze (Dembowsky et al., 1985; Shen et al., 1990). Despite being shown to be selective for the $\mathrm{A} 2{ }_{\mathrm{A}} \mathrm{R}$, it has been reported that CGS 21680 at micromolar concentrations may weakly activate the A1R (Li and Henry, 1998), which does appear to be functional in this region of the spinal cord (Deuchars et al., 2001b). Hence, for some experiments, CGS 21680 was applied in the presence of the A1R antagonists 8-cyclopentyl-1,3-dipropylxanthine (DPCPX) (50 nM; $n=7)$ or CPT (10 $\mu \mathrm{M} ; n=25)$. Administration of DPCPX (50 nM) or CPT (10 $\mu \mathrm{M})$ alone had no effect on the evoked EPSP as expected (results not shown; Deuchars et al., 2001b). No significant effect was observed on the evoked EPSP in
A
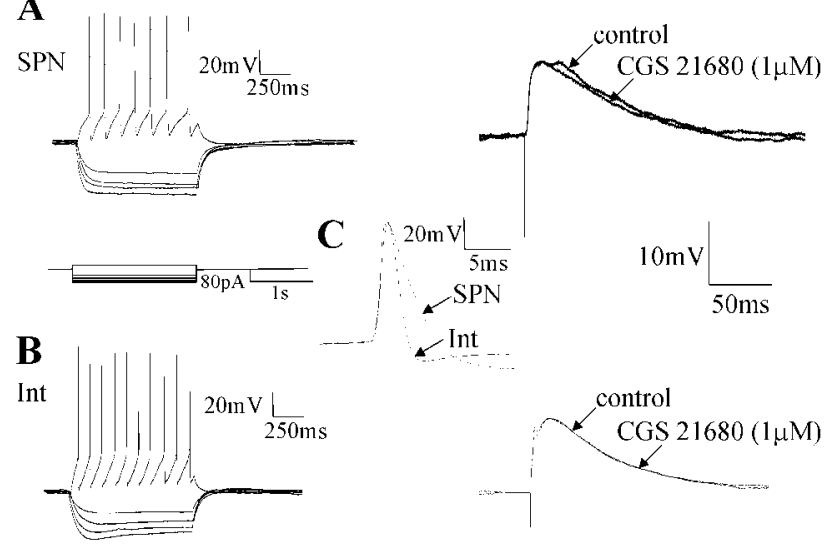

Int

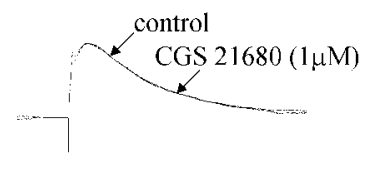

D

$\mathbf{E} \ln \operatorname{DPCPX}(50 \mathrm{nM})$
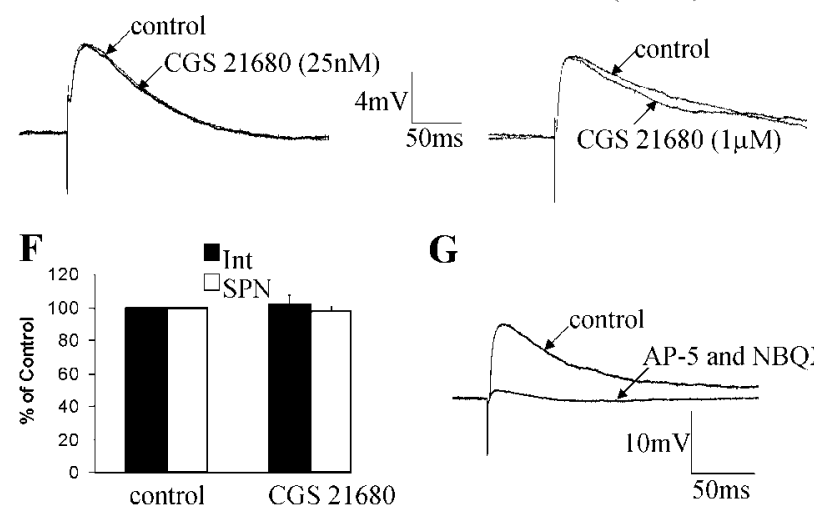

G

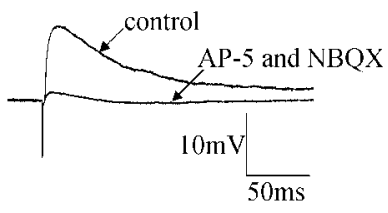

Figure 4. The adenosine $A 2_{A}$ receptor agonist CGS 21680 does not affect the amplitude of EPSPs elicited in SPNs and interneurons. A, Left, Voltage responses of an SPN to hyperpolarizing and depolarizing current pulses. A delayed return to resting potential at the end of the hyperpolarizing current pulse is evident, indicative of activation of an $I_{A}$. Right, An EPSP was not significantly affected by CGS $21680(1 \mu \mathrm{M})$. B, Left, Voltage responses of an interneuron (Int) to the same hyperpolarizing and depolarizing current pulses. At hyperpolarized potentials, a sag in the voltage response was seen, suggesting activation of an $I_{H}$ current. The action potential was short, and the AHP displayed distinct fast and slow phases. Right, Evoked EPSP elicited in the interneuron. The EPSP amplitudes are not significantly different from those elicited in the SPNs. In addition, CGS $21680(1 \mu \mathrm{M})$ had no effect on the interneuronal EPSP. C, Comparison of the interneuronal and SPN action potentials and AHPs illustrating the shorter half-width of interneuronal action potentials. The SPN action potential shows the characteristic hump on the repolarization phase. D, EPSP elicited in an interneuron. CGS 21680 (25 nM) had no significant effect on the evoked EPSP. E, EPSP elicited in an SPN. CGS $21680(1 \mu \mathrm{M})$ administered in the presence of DPCPX had no significant effect on the evoked EPSP. F, Pooled data showing that CGS $21680(1 \mu \mathrm{m})$ has no significant effect on EPSPs elicited in SPNs or interneurons. $G$, In another SPN, the EPSP was abolished by application of the excitatory amino acid antagonists $\operatorname{NBQX}(20 \mu \mathrm{m})$ and AP-5 $(50 \mu \mathrm{m})$.

interneurons after the application of CGS 21680 alone (25 nM, $6.5 \pm 0.4$ to $6.5 \pm 0.4 ; n=5$; Fig. $4 D ; 1 \mu \mathrm{M}, 8.5 \pm 1.9$ to $8.3 \pm 1.3$; $n=4$; Fig. $4 B)$ or in the presence of $50 \mathrm{~nm} \mathrm{DPCPX}(1 \mu \mathrm{M}, 7.5 \pm$ 1.6 to $7.1 \pm 1.5 ; n=4)$ or $10 \mu \mathrm{M} \mathrm{CPT}(1 \mu \mathrm{M}, 6.2 \pm 0.7$ to $5.8 \pm$ $0.9 ; n=5)$. Similar results were obtained in SPNs with CGS 21680 having no effect on the evoked EPSP when added alone $(25 \mathrm{nM}$, $6.4 \pm 0.6$ to $6 \pm 0.7 ; 1 \mu \mathrm{M}, 6.2 \pm 1.1$ to $6 \pm 0.8 ; n=6$; Fig. $4 A$ ) or in the presence of $50 \mathrm{~nm} \mathrm{DPCPX} \mathrm{(6.9 \pm 1.1} \mathrm{to} 7.1 \pm 0.7 ; n=3$; Fig. $4 \mathrm{E})$ or $10 \mu \mathrm{M} \mathrm{CPT}(5.3 \pm 0.3$ to $5.3 \pm 0.4 ; n=20)$. The duration, rise time, and decay time of the EPSP were also unaffected because the EPSP shape was identical in the presence of CGS 21680 (applied for up to $20 \mathrm{~min}$ ) compared with control (Fig. 4A-E). These EPSPs could be abolished by applications of 
NBQX $(20 \mu \mathrm{M})$ and AP-5 (50 $\mu \mathrm{M}$; Fig. $4 G)$, as expected (Deuchars et al., 1995), showing that these responses are elicited by an excitatory amino acid. Thus, $\mathrm{A}_{2}{ }_{\mathrm{A}} \mathrm{Rs}$ do not appear to modulate excitatory amino acid transmission in the IML region.

Fast IPSPs elicited by If stimulation are increased in amplitude by applications of CGS 21680

Stimulating the lateral funiculus activates both excitatory and inhibitory descending pathways (Deuchars et al., 1997). Therefore, the effects of CGS 21680 on these inhibitory inputs onto the SPNs and interneurons were investigated. In control conditions, the response observed with lf stimulation was an EPSP that was not significantly different in amplitude or latency for SPNs and interneurons and was not significantly affected by applications of CGS 21680. To determine whether there was an inhibitory input onto these neurons, the neurons were depolarized to -10 to $-20 \mathrm{mV}$ to increase the driving force for chloride ions and enhance the IPSP amplitude. If an IPSP was not observed in control conditions, NBQX and AP-5 were administered to uncover an IPSP. DPCPX and CPT were not included in the bathing medium because activation of AlRs with CPA had no effect on IPSP amplitude in SPNs or interneurons (Deuchars et al., 2001b).

Consistent with the IPSPs in both SPNs and interneurons arising from both monosynaptic and polysynaptic pathways, they were reduced in amplitude but never completely blocked by applications of NBQX and AP-5 $(n=13)$. Applications of bicuculline $(n=10)$ partly blocked the IPSPs, indicating a $\mathrm{GABA}_{\mathrm{A}}$ receptormediated component, whereas the remaining component was abolished by strychnine $(n=8$; Fig. $5 A)$. In the presence of NBQX (20 $\mu \mathrm{M})$ and AP-5 $(50 \mu \mathrm{M})$, bicuculline $(10 \mu \mathrm{M})$ abolished the IPSP $(n=$ 3; Fig. 5B). These results indicate that the fast IPSPs elicited by lf stimulation in neurons of the IML are likely to be mediated by monosynaptic GABAergic and polysynaptic glycinergic pathways. In support of this, there is evidence of a monosynaptic descending GABAergic pathway onto SPNs (Deuchars et al., 1997) but little evidence of a descending monosynaptic glycinergic pathway.

CGS $21680(1 \mu \mathrm{M})$ increased the amplitude of all evoked IPSPs in the control solution from $10.2 \pm 2.2$ to $13.7 \pm 2.8 \mathrm{mV}$ in SPNs $(n=6 ;$ Fig. $5 C, D)$, an increase of $35 \pm 8.6 \%$, and in interneurons from $5.0 \pm 0.5$ to $7.1 \pm 0.8 \mathrm{mV}(n=20$; Fig. $5 C, D)$, an increase of $41 \pm 7 \%$. Peak responses were reached after $3-5$ min incubation in CGS 21680. Recovery was obtained on washout (Fig. 5C), and these effects were reproducible on reapplication of the agonist. Because IPSPs in SPNs and interneurons comprised GABAergic and glycinergic components, we investigated whether CGS 21680 affected these components differentially. The data for the two types of neurons were pooled for clarity because the effects were the same. In NBQX $(20 \mu \mathrm{M})$ and AP-5 $(50 \mu \mathrm{M})$, CGS 21680 still increased IPSP amplitudes ( $6.4 \pm 1.6$ to $8.9 \pm 2.1 \mathrm{mV}$, an increase of $29 \pm 5.8 \% ; n=11$; Fig. $5 E$ ), indicating that $\mathrm{A}_{\mathrm{A}} \mathrm{Rs}$ are located on terminals likely arising from a monosynaptic GABAergic pathway. Similarly, the bicuculline-insensitive component of IPSPs that was abolished by strychnine was increased in amplitude by CGS 21680 from $8.3 \pm 2.1$ to $10.3 \pm 2.1 \mathrm{mV}$ ( $n=4$; Fig. $5 F$ ), indicating that the $\mathrm{A}_{\mathrm{A}} \mathrm{Rs}$ are also likely to be located on inhibitory glycinergic terminals. Thus, CGS 21680 increases the amplitude of both GABA- and glycine-mediated IPSPs onto SPNs and interneurons.

The effects of CGS 21680 could be antagonized by the $A 2_{A} R$ antagonist ZM 241385

The $\mathrm{A} 2{ }_{\mathrm{A}} \mathrm{R}$ antagonist $\mathrm{ZM} 241385(1 \mu \mathrm{M})$ was applied to both SPNs and interneurons in an attempt to selectively block the increase observed with CGS 21680. ZM 241385 was either applied
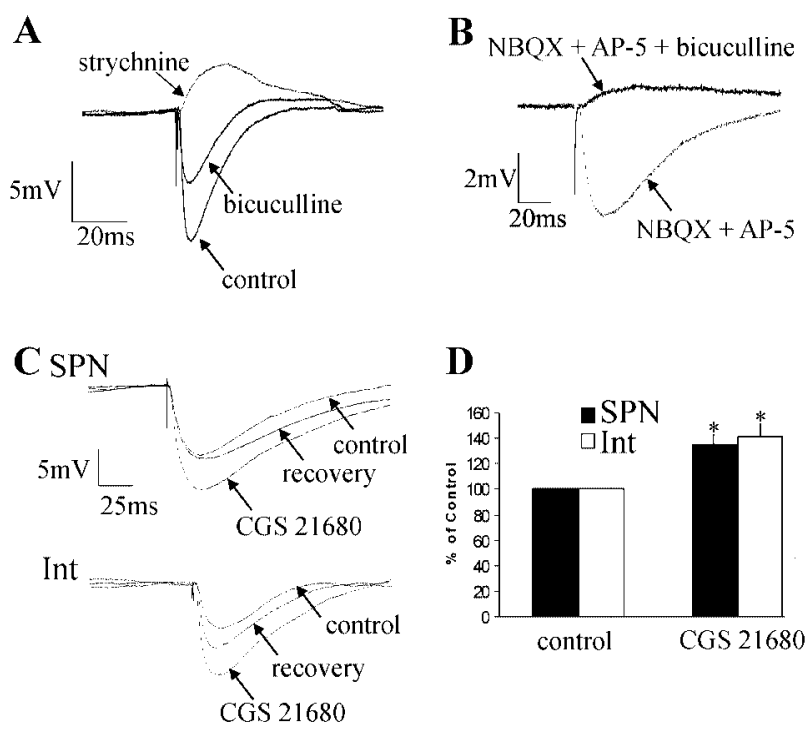

D
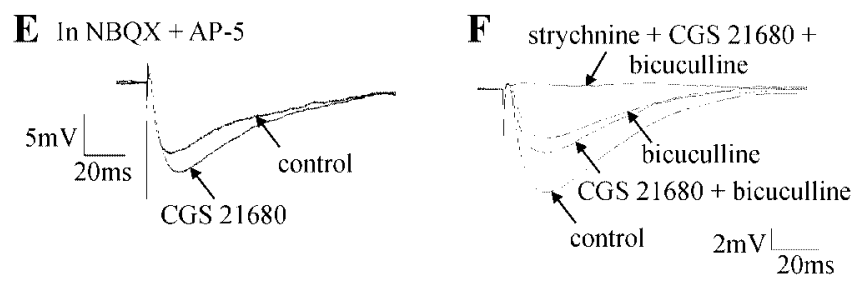

Figure 5. The adenosine $A 2_{A}$ receptor agonist CGS 21680 increases the amplitude of IPSPS elicited in SPNs and interneurons. $A$, Evoked IPSP, which was partially blocked by bicuculline (10 $\mu \mathrm{M})$ and abolished by the subsequent application of $1 \mu \mathrm{m}$ strychnine. $B$, An IPSP in the presence of NBQX (20 $\mu \mathrm{M})$ and AP-5 $(50 \mu \mathrm{m})$ was completely blocked by the subsequent application of bicuculline $(10 \mu \mathrm{M})$. C, Top, An IPSP elicited in the same SPN as shown in Figure 4A. CGS 21680 $(1 \mu \mathrm{m})$ increased the amplitude of the IPSP from 5.5 to $10.8 \mathrm{mV}$. Bottom, IPSP elicited in the same interneuron (Int) as shown in Figure 4B. CGS $21680(1 \mu \mathrm{m})$ increased the IPSP amplitude from 8.4 to $11.5 \mathrm{mV}$. D, Pooled data showing that $1 \mu \mathrm{M}$ CGS 21680 increased the amplitude of IPSPs elicited in SPNs and interneurons and that this effect was not significantly different between the two types of neurons. * ${ }^{*}$ Significance at $p>0.05$. E, IPSP elicited in an interneuron in the presence of the excitatory amino acid antagonists NBQX (20 $\mu \mathrm{M})$ and AP-5 $(50 \mu \mathrm{m})$. The IPSP remained in the presence of NBQX and AP-5, and this remaining component was increased in amplitude by $\operatorname{CSS} 21680(1 \mu \mathrm{M})$. F, Evoked IPSP in an SPN, which was reduced in amplitude by bicuculline (10 $\mu \mathrm{M})$. CGS $21680(1 \mu \mathrm{m})$ enhanced the amplitude of the bicuculline-insensitive component, which was abolished by the subsequent application of strychnine $(1 \mu \mathrm{M})$.

during application of CGS 21680 in which the IPSP had been increased or applied before CGS 21680 application. CGS 21680 increased the IPSP amplitude from $5.7 \pm 1.2$ to $7.5 \pm 1.9 \mathrm{mV}$ $(n=6$; Fig. $6 D)$. ZM 241385 antagonized the effects of CGS 21680 after 5 min incubation, and the IPSP amplitude returned to $6.4 \pm 1.4 \mathrm{mV}$ (Fig. 6A,D). On two occasions, ZM 241385 was preincubated for $10 \mathrm{~min}$ before CGS 21680 application. Under these conditions, CGS 21680 failed to increase the IPSP amplitude (Fig. $6 \mathrm{~B}$ ). After washout of both drugs, application of CGS 21680 alone increased the IPSP amplitude (Fig. 6 B, right), showing that the effect of ZM 41385 was indeed attributable to blockade of the $\mathrm{A} 2_{\mathrm{A}} \mathrm{Rs}$.

ZM 241385 was also applied alone for up to $10 \mathrm{~min}$ to determine whether basal adenosine levels are sufficient to tonically activate $\mathrm{A} 2{ }_{\mathrm{A}} \mathrm{Rs}$. ZM $241385(1 \mu \mathrm{M})$ had no effect on the evoked IPSP $(n=5$; Fig. $6 C, D)$ or holding potential. Thus, in our recording conditions, basal adenosine levels are not sufficient to tonically activate the $\mathrm{A} 2_{\mathrm{A}} \mathrm{Rs}$. 


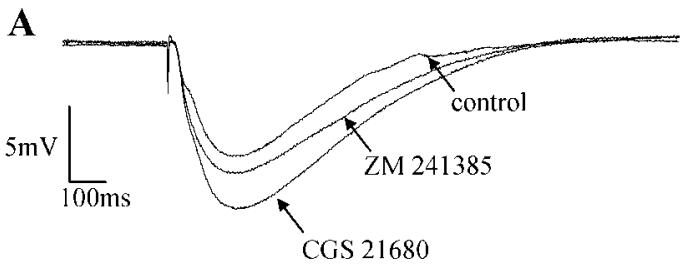

B In ZM 241385: wash:
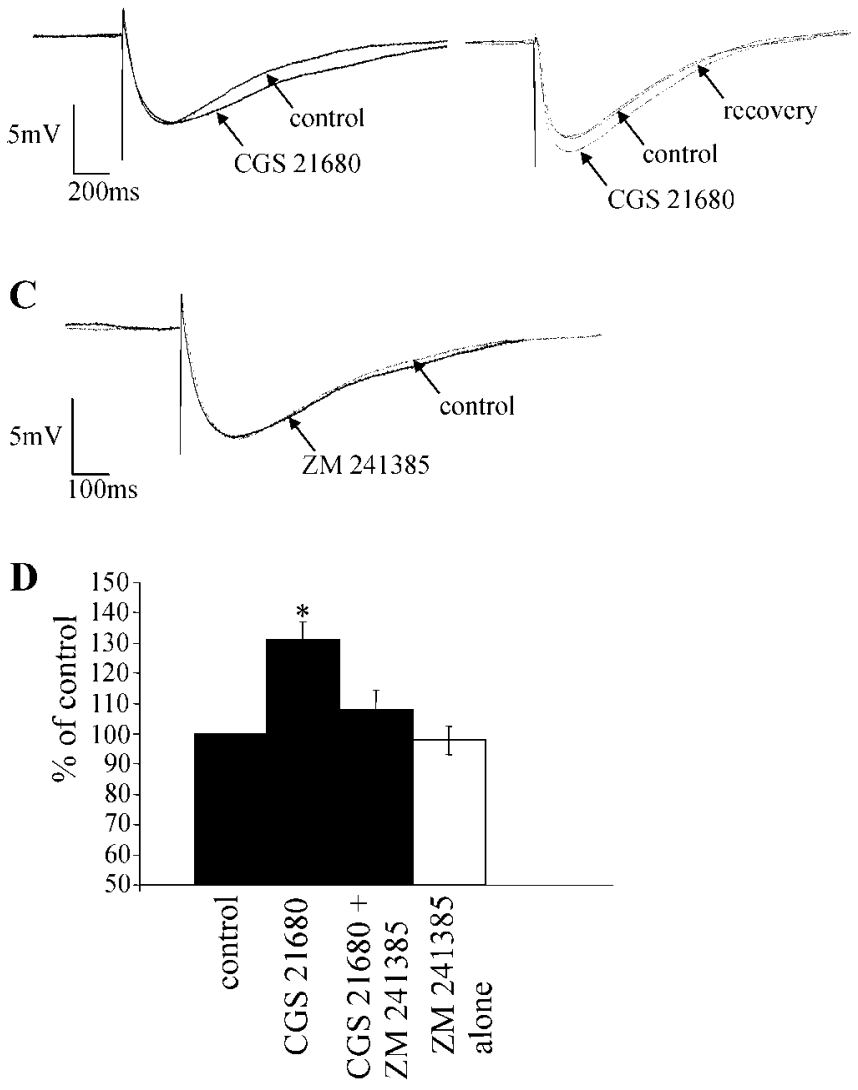

Figure 6. The effects of CGS 21680 are antagonized by the adenosine $A 2_{A}$ receptor antagonist ZM 241385. A, IPSP elicited in an interneuron. CGS $21680(1 \mu \mathrm{M})$ increased the amplitude of the IPSP, an effect that was antagonized by subsequent application of ZM $241385(1 \mu \mathrm{M}) . B$, Left, IPSP in an interneuron in the presence of $1 \mu \mathrm{M}$ ZM 241385. After preincubation of ZM 241385, CGS $21680(1 \mu \mathrm{M})$ failed to induce an increase in IPSP amplitude. Right, IPSP after washout of the drugs. The ability of CGS 21680 to increase the IPSP amplitude returned on washout of ZM 241385, indicating that preincubation of ZM 241385 blocked the effect of CGS 21680. C, Administration of ZM $241385(1 \mu \mathrm{M})$ alone had no effect on the IPSP amplitude. D, Pooled data showing that CGS $21680(1 \mu \mathrm{M})$ significantly increases IPSP amplitude and that this effect is antagonized by $1 \mu \mathrm{m}$ ZM 241385. ZM 241385 alone has no effect on IPSP amplitude. *Significance at $p>0.05$.

The effects of CGS 21680 on IPSP amplitude are attributable to a presynaptic action

To determine whether the regulation of inhibitory synaptic transmission in the IML was mediated by presynaptic $\mathrm{A} 2{ }_{\mathrm{A}} \mathrm{Rs}$, postsynaptic $\mathrm{A} 2{ }_{\mathrm{A}} \mathrm{Rs}$, or both, the effect of CGS 21680 on paired pulse ratios was examined. The relative amplitude of the synaptic response to two stimuli applied to the lf at short intervals was determined in control aCSF and in CGS 21680. In the control solution, the paired pulse ratio was $1.4 \pm 0.1(n=7)$, which is paired pulse facilitation. When CGS 21680 was applied, the first IPSP increased in amplitude, and the paired pulse ratio decreased to $0.9 \pm 0.1$, a significant change from the control ratio of 1.4 (Fig. $7 A, B$ ). Thus, there was a switch from paired pulse facilita-

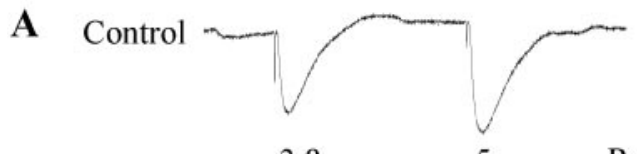

$3.8 \quad 5 \quad$ Ratio $1: 1.3$
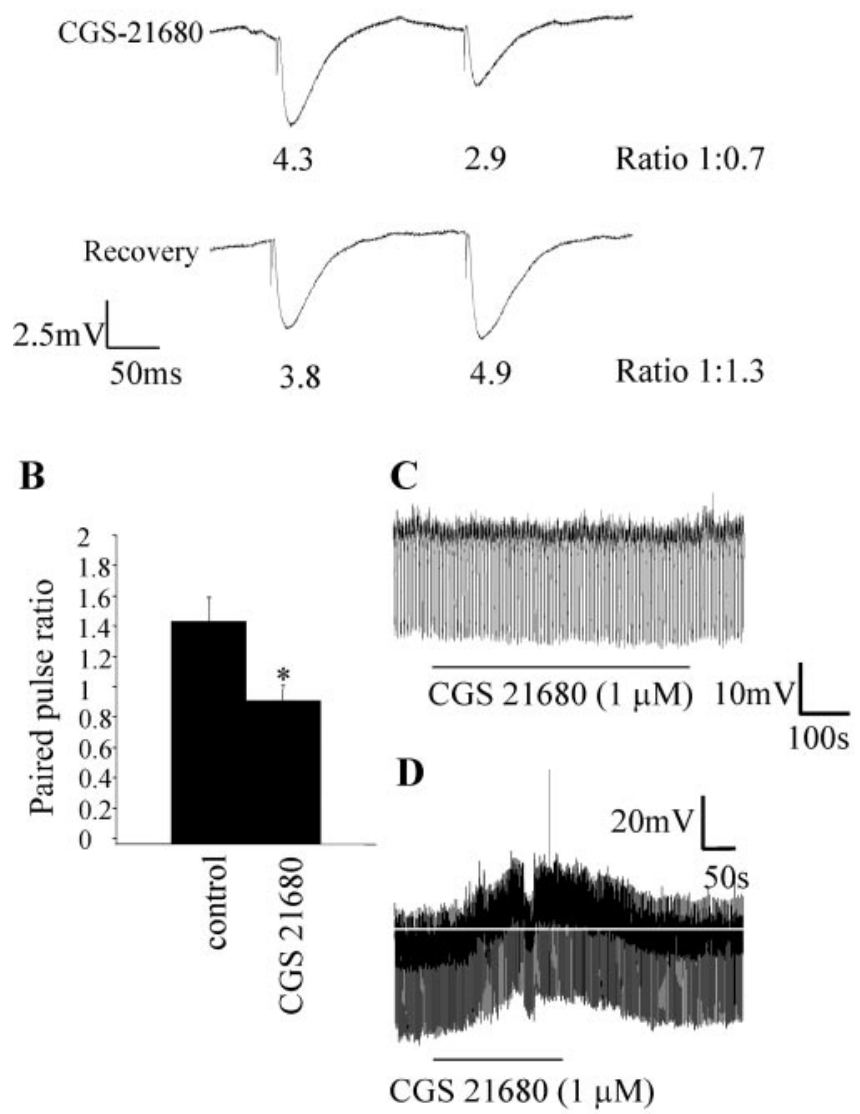

Figure 7. The effects of the adenosine $A 2_{A}$ receptor agonist CGS 21680 are attributable primarily to a presynaptic site of action. $A$, Responses of an SPN to twin-pulse stimulation of the lateral funiculus in the control solution showed paired pulse facilitation; i.e., the response to the second stimulus was larger than the first. In $1 \mu \mathrm{M}$ CGS 21680, the second response was smaller than the first response, with the ratio decreasing to 1:0.7. This change in ratio is indicative of a presynaptic site of action of CGS 21680. On washout of CGS 21680, the ratio returned to the control value of 1:1.3. B, Pooled data showing that $1 \mu \mathrm{M}$ CGS 21680 altered the paired pulse ratio $(n=7)$. ${ }^{*}$ Significance at $p>0.05$. C, Hyperpolarizing current pulses $(30 \mathrm{pA})$ were applied to an SPN (held at $-65 \mathrm{mV}$ ), and $1 \mu \mathrm{M}$ CGS 21680 was administered. There was no change in membrane potential or input resistance with CGS 21680 application. D, Example of a neuron in which a change in membrane potential was observed on administration of $1 \mu \mathrm{m}$ CGS 21680. CGS 21680 caused a small depolarization $(4 \mathrm{mV})$, which was not associated with a change in input resistance.

tion to paired pulse depression (Fig. 7B), implying a presynaptic site of action of CGS 21680.

In the majority of neurons, evidence for a postsynaptic action was not observed because there was no change in holding potential or input resistance (Fig. $7 C$ ). In only 3 of 20 neurons tested was a small depolarization (3, 4, and $2 \mathrm{mV}$, respectively; Fig. 7D) observed in the presence of CGS 21680, which returned to baseline on washout of the drug. Interestingly, this was not associated with a change in input resistance, contrary to what would be expected if the depolarization was solely attributable to the closure of potassium channels. Furthermore, at more depolarized potentials at which the driving force for potassium is higher, CGS 21680 never caused a change in holding potential. These data 
A

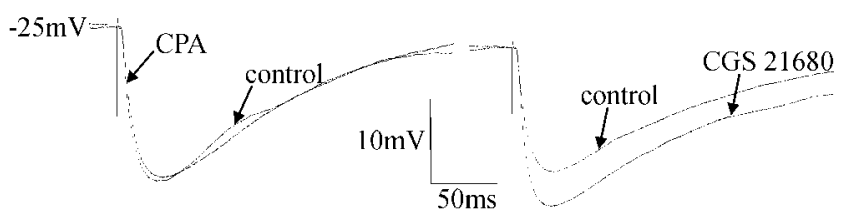

B

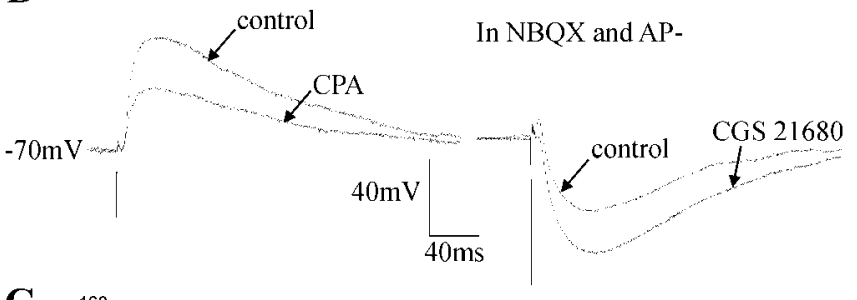

C

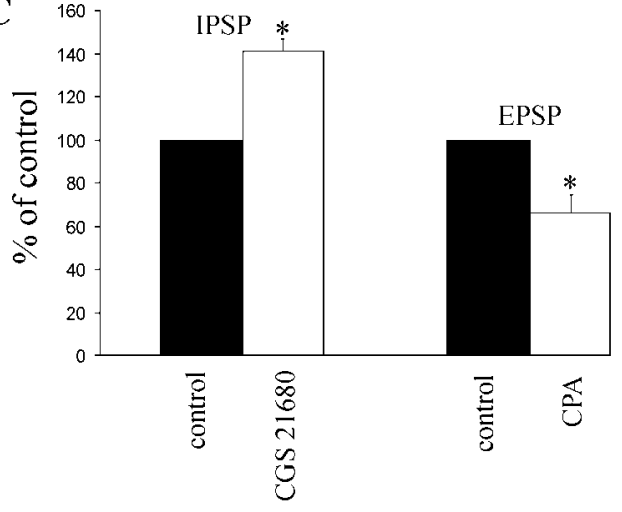

Figure 8. Selective modulation of excitatory and inhibitory synaptic inputs onto the same neuron by $A 1$ and $A 2_{A}$ adenosine receptors. $A$, Left, IPSP elicited in an SPN in control conditions and in the presence of (PA (100 nM). CPA had no effect on the amplitude of the IPSP. Right, After washout of CPA, CGS $21680(1 \mu \mathrm{m})$ was applied, and an increase in the IPSP amplitude was obtained (20.6 to $26.6 \mathrm{mV}$ ). B, Left, EPSP elicited in an interneuron in control conditions and in the presence of CPA. CPA (100 nM) decreased the amplitude of the EPSP from 6.7 to $3.6 \mathrm{mV}$. Right, IPSP elicited in the same interneuron in the presence of NBQX $(20 \mu \mathrm{M})$ and AP-5 $(50 \mu \mathrm{M})$, observed at $-20 \mathrm{mV}$. CGS $21680(1 \mu \mathrm{m})$ increased the IPSP amplitude from 4.6 to $6.3 \mathrm{mV}$. C, Pooled data showing that $1 \mu \mathrm{M}$ CGS 21680 increased the amplitude of evoked IPSPs, and $100 \mathrm{~nm}$ CPA decreased the amplitude of EPSPs elicited in the same neurons $(n=5)$. ${ }^{*}$ Significance at $p>0.05$.

therefore indicate that in the IML, the major site of action of the $\mathrm{A} 2{ }_{\mathrm{A}} \mathrm{R}$ is presynaptic. This is in accordance with previous reports indicating that the effects of activating $\mathrm{A} 2{ }_{\mathrm{A}} \mathrm{Rs}$ are attributable primarily to $\mathrm{A} 2{ }_{\mathrm{A}} \mathrm{Rs}$ located presynaptically in many CNS regions (Mori et al., 1996; Shindou et al., 2001, 2002).

Adenosine $A 1$ and $A 2_{A}$ receptors are located on excitatory and inhibitory terminals, respectively synapsing onto the same neurons in the IML

As previously reported, A1Rs are located exclusively on excitatory, not inhibitory, terminals, which synapse onto SPNs and interneurons in the IML (Deuchars et al., 2001b). In this study, we have shown that $\mathrm{A} 2{ }_{\mathrm{A}} \mathrm{Rs}$ are functionally located exclusively on inhibitory terminals, which also synapse onto SPNs and interneurons. Thus, we next investigated the possibility that a single neuron in the IML may receive inputs from both excitatory and inhibitory terminals expressing $\mathrm{A} 1$ and $\mathrm{A} 2{ }_{\mathrm{A}}$ receptors, respectively. All neurons tested ( $n=5$ of 5 ) receiving excitatory inputs that were reduced by $\mathrm{CPA}(8.6 \pm 1.8$ to $5.2 \pm 1.1 \mathrm{mV} ; 37 \%$ decrease; $p<0.05$; Fig. $8 B$ ) also received inhibitory inputs that were increased by CGS 21680 (5.1 \pm 0.6 to $7.2 \pm 0.1 \mathrm{mV} ; 41 \%$
IML
Inhibitory terminal

\section{Excitatory terminal}

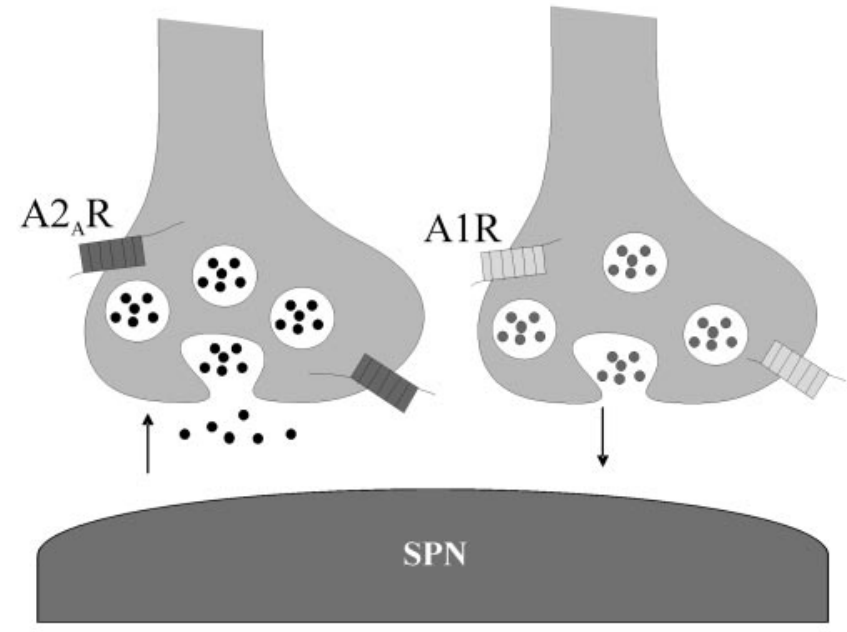

Figure 9. The distribution of adenosine $\mathrm{A} 1$ and $A 2_{A}$ receptors is input specific. This drawing summarizes the distribution of adenosine receptors in the IML of the thoracic spinal cord. A1Rs are located exclusively on excitatory terminals, whereas $A 2_{A} R s$ are targeted to inhibitory synaptic inputs. Once activated, $A 2_{A} R s$ increase neurotransmitter release, whereas $A 1 R s$ decrease release, from their respective terminals.

increase; $p<0.05$; Fig. $8 B, C)$. Thus, there does appear to be a very distinct segregation of $\mathrm{A} 1$ and $\mathrm{A} 2{ }_{\mathrm{A}}$ receptors on excitatory and inhibitory terminals, respectively, that innervate the same neurons. This is the first study providing evidence of an overall inhibitory effect of adenosine on single neurons after dual activation of $\mathrm{A} 1$ and $\mathrm{A} 2{ }_{\mathrm{A}}$ receptors.

\section{Discussion}

The electrophysiological and anatomical data presented here indicate that $\mathrm{A} 2{ }_{\mathrm{A}} \mathrm{Rs}$ are functionally located on inhibitory terminals, where they increase inhibitory neurotransmission onto SPNs and interneurons in the IML. This is the first study providing evidence of a selective effect of $\mathrm{A} 2{ }_{\mathrm{A}} \mathrm{Rs}$ on inhibitory but not excitatory transmission onto the same neuron. Indeed, we have shown that both $\mathrm{A} 2{ }_{\mathrm{A}}$ and $\mathrm{A} 1$ receptors are functional presynaptically on different inputs onto the same neuron (Fig. 9). These data, in conjunction with our previous work (Deuchars et al., 2001b), provide a possible mechanism whereby adenosine can induce cardiovascular variables, as reported by Koh et al. (1996, 2000), via $A 2{ }_{A}$ Rs and A1Rs working synergistically to depress sympathetic outflow. These studies are also pertinent because previous anatomical studies failed to provide evidence supporting the presence of $\mathrm{A} 2{ }_{\mathrm{A}} \mathrm{Rs}$ in sympathetic regions of the spinal cord (Choca et al., 1987, 1988; Kaelin-Lang et al., 1999).

\section{$\mathrm{A} 2{ }_{\mathrm{A}}$ Rs enhance IPSPs but not EPSPs}

Stimulation of the lf elicited EPSPs and IPSPs in SPNs and interneurons, so the effects of CGS 21680 on excitatory and inhibitory neurotransmission in the same neuron could be examined. These interneurons are likely to be involved in sympathetic control because all interneurons in this region have sympathetic-correlated activity (Chau et al., 2000), and some are antecedent to SPNs (Joshi et al., 1995; Brooke et al., 2002). CGS 21680 selectively enhanced IPSP amplitudes in SPNs and interneurons, an effect mediated via $\mathrm{A} 2{ }_{\mathrm{A}} \mathrm{Rs}$ because CGS 21680 is an $\mathrm{A} 2{ }_{\mathrm{A}} \mathrm{R}$-selective agonist (Jarvis and Williams, 1989), and this effect was blocked by the $\mathrm{A} 2{ }_{\mathrm{A}} \mathrm{R}$-selective antagonist ZM 241385 (Poucher et al., 1995). 
In contrast to the A1R function in this region (Deuchars et al., 2001b), activation of $\mathrm{A} 2{ }_{\mathrm{A}} \mathrm{Rs}$ with CGS 21680 had no effect on EPSP amplitude.

Excitotoxic effects of hypoxia and ischemia are attributable, in part, to excessive release of glutamate (Hara et al., 1993; Schroder et al., 1999). Under these conditions, the concentration of adenosine available increases and activates A1Rs to reduce excitotoxicity (Fowler, 1989; Simpson et al., 1992; Katchman and Hershkowitz, 1993; Sweeney, 1997). A2 ${ }_{\mathrm{A}} \mathrm{Rs}$ are often considered excitatory, potentiating the release of excitatory neurotransmitters (Sebastiao and Ribeiro, 1996). Thus, although mechanisms underlying the role of $\mathrm{A} 2{ }_{\mathrm{A}} \mathrm{Rs}$ during periods of metabolic stress are unclear, $\mathrm{A} 2{ }_{\mathrm{A}} \mathrm{R}$ antagonists are potentially neuroprotective after ischemia because they offset the effects of released excitatory amino acids (Ongini et al., 1997; Jones et al., 1998; Pedata et al., 2001). In contrast, there are recent reports of a neuroprotective role of $\mathrm{A} 2{ }_{\mathrm{A}} \mathrm{Rs}$ (Aden et al., 2003; Blum et al., 2003), and, importantly, our data show how, in the spinal cord, $\mathrm{A} 2{ }_{\mathrm{A}} \mathrm{R}$ activation, rather than blockade, may also be neuroprotective by increasing inhibitory neurotransmission, thus reducing postsynaptic neuronal excitability. This is crucial in the spinal cord because disruption of sympathetic outflow, which is partly to the heart and blood vessels, could have potentially fatal repercussions.

Despite detecting postsynaptic immunostaining in the IML, evidence for functional postsynaptic $\mathrm{A} 2{ }_{\mathrm{A}}$ Rs was rarely observed. This may be because postsynaptic $\mathrm{A} 2{ }_{\mathrm{A}} \mathrm{Rs}$ act via an interaction with another receptor type (see below) or because $\mathrm{A} 2{ }_{\mathrm{A}} \mathrm{Rs}$ are produced in the postsynaptic neuron and transported to the terminals. Occasionally, in agreement with studies describing postsynaptic effects of $\mathrm{A}_{2}{ }_{\mathrm{A}} \mathrm{Rs}$ ( $\mathrm{Li}$ and Henry, 1998), a small depolarization was seen in the postsynaptic neuron. Contrary to what would be expected if depolarization resulted from a decrease in potassium conductance, this depolarization was never associated with changes in input resistance. However, our data imply that the major effect of the $\mathrm{A} 2{ }_{\mathrm{A}} \mathrm{R}$ in the IML is presynaptic. This fits with a neuroprotective role for adenosine because postsynaptic depolarizing effects would increase neuronal excitation and counteract the inhibition produced presynaptically via $\mathrm{A} 2{ }_{\mathrm{A}} \mathrm{Rs}$ and, indeed, A1Rs (Deuchars et al., 2001b).

\section{$\mathrm{A} 2{ }_{\mathrm{A}} \mathrm{R}$ interactions}

$\mathrm{A} 2{ }_{\mathrm{A}} \mathrm{Rs}$ can interact with other receptors, such as dopamine (Ferre et al., 1997), calcitonin-related peptide (Correia-de-Sa and Ribeiro, 1994a), metabotropic glutamate (Winder and Conn, 1993), nicotinic (Correia-de-Sa and Ribeiro, 1994b), and adenosine A1 (Lopes et al., 1999b) receptors. Thus, CGS 21680 may produce no observable effects on an EPSP unless coactivation of the receptor with which it is interacting occurs. One candidate is the A1R because it is also located in the IML, and tonic A1R activation was required for CGS 21680-induced facilitation of synaptic transmission in hippocampus and cortex (Lopes et al., 1999a). However, A1Rs are not tonically active in this preparation (Deuchars et al., 2001b; this study) and are not present on inhibitory terminals, which are shown here to possess functional $\mathrm{A} 2{ }_{\mathrm{A}}$ Rs. Thus, in the IML, we provide evidence in support of an input-specific localization of different adenosine receptor subtypes in the IML.

\section{Source and pharmacology of the presynaptic terminals}

The presence of $\mathrm{A} 2{ }_{\mathrm{A}} \mathrm{R}$ immunoreactivity in the lf and the fact that stimulating the lf elicited IPSPs that were increased in amplitude by CGS 21680 suggest that the $\mathrm{A} 2{ }_{\mathrm{A}} \mathrm{Rs}$ may be located on presynaptic inhibitory terminals of descending fibers from higher cen- ters. SPNs are innervated by direct inputs from supraspinal regions, including the A5 region of the pons, raphe nuclei, paraventricular nucleus, lateral hypothalamus, and rostral ventrolateral medulla (RVLM) (Strack et al., 1989) and also via inputs from propriospinal pathways, which originate in the cervical spinal cord (Schramm and Livingstone, 1987). All these regions may give rise to $\mathrm{A} 2{ }_{\mathrm{A}} \mathrm{R}$-positive terminals in the IML; however, the RVLM is a particularly likely candidate. Direct evidence for an inhibitory GABAergic pathway from the RVLM onto SPNs (and indirect evidence for this pathway impinging onto interneurons) in the IML has been reported (Deuchars et al., 1997). Also, $\mathrm{A} 2{ }_{\mathrm{A}} \mathrm{R}$ immunoreactivity has been shown in the RVLM (Rosin et al., 1998), supporting the possibility that neurons in this region produce the $\mathrm{A} 2{ }_{\mathrm{A}} \mathrm{R}$ and then transport it to their terminals in the IML.

Our results are consistent with there being a descending monosynaptic GABAergic pathway because IPSPs elicited by lf stimulation remained in the presence of AP-5 and NBQX and were blocked by bicuculline. These excitatory amino acid antagonists block polysynaptic IPSPs elicited by stimulation of the RVLM (Deuchars et al., 1997). In some neurons, bicuculline only partially blocked the IPSPs. Subsequent application of strychnine abolished the remaining component, suggesting that some of the IPSPs have both GABAergic and glycinergic components. There is no evidence to suggest the existence of a monosynaptic descending glycinergic pathway to the IML, so these data provide evidence to suggest that the inhibitory inputs are likely to arise from a monosynaptic GABAergic pathway and a polysynaptic glycinergic component. In the presence of AP-5 and NBQX, CGS 21680 still induced an enhancement of the IPSP, indicating that $\mathrm{A} 2{ }_{\mathrm{A}} \mathrm{Rs}$ are located on the GABAergic terminals. CGS 21680 also increased the amplitude of the strychnine-sensitive, bicucullineinsensitive IPSPs, demonstrating that the $\mathrm{A} 2{ }_{\mathrm{A}} \mathrm{Rs}$ are also located on the glycinergic terminals.

\section{Preferential activation of $\mathrm{A} 1$ or $\mathrm{A} 2 \mathrm{~A}$ receptors?}

Other studies have reported that $\mathrm{A} 1$ and $\mathrm{A} 2{ }_{\mathrm{A}}$ receptors are often expressed in the same regions [e.g., hippocampus (Cunha et al., 1994) and neuromuscular junction (Correia-de-Sa et al., 1996)] and indeed on the same nerve terminals at the neuromuscular junction (Correia-de-Sa et al., 1996). The coexistence of both subtypes of high-affinity adenosine receptors leads to the question of which receptor adenosine preferentially activates. Most studies using adenosine itself, rather than adenosine analogs, to investigate adenosine receptor actions reported inhibitory effects. These are primarily attributable to activation of A1Rs, and this has resulted in the classical view that endogenous adenosine preferentially activates A1Rs. For example, in the dorsal horn, administration of adenosine results in a depression of EPSPs and hyperpolarization; this effect was mimicked by an A1R agonist but not by an $\mathrm{A} 2{ }_{\mathrm{A}} \mathrm{R}$ agonist (Patel et al., 2001). Despite this, it has been suggested that activation of specific adenosine receptor subtypes by endogenous adenosine is dependent on the origin of adenosine. There is some evidence that only adenosine released as such acts on A1Rs, whereas adenosine formed from adenine nucleotides preferentially activates $\mathrm{A} 2_{\mathrm{A}} \mathrm{Rs}$ (Cunha et al., 1996). In regions where $\mathrm{A} 1$ and $\mathrm{A} 2{ }_{\mathrm{A}}$ receptors have opposing actions, the answer to this question is perhaps slightly more important if one is to understand the overall role of adenosine. However, the data presented here indicate that, regardless of whether adenosine activates $\mathrm{A} 1$ or $\mathrm{A} 2{ }_{\mathrm{A}}$ receptors, the overall effect is the same, a decrease in neuronal excitability. This is pertinent because in this region, the source of adenosine and the conditions under which it is released are unresolved. In other autonomic regions, a major 
source of adenosine may be attributable to the extracellular metabolism of ATP (St. Lambert et al., 1997), and because SPNs are excited by activation of the $\mathrm{P}_{2} \mathrm{X}_{7}$ receptor, whose endogenous ligand is ATP (Deuchars et al., 2001c), it is likely that this is the case in the IML.

We have established that adenosine $\mathrm{A} 2{ }_{\mathrm{A}} \mathrm{Rs}$ are located on inhibitory presynaptic terminals innervating SPNs and interneurons in the IML. Activation of these receptors increases the release of transmitter from these inhibitory terminals. We therefore conclude that adenosine acting on $\mathrm{A} 2{ }_{\mathrm{A}} \mathrm{Rs}$ may play an important role in regulating sympathetic nervous system activity at the level of the spinal cord.

\section{References}

Aden U, Halldner L, Lagercrantz H, Dalmau I, Ledent C, Fredholm BB (2003) Aggravated brain damage after hypoxic ischemia in immature adenosine A2A knockout mice. Stroke 34:739-744.

Ambalavanar R, Morris R (1989) Fluoro-gold injected either subcutaneously or intravascularly results in extensive retrograde labelling of CNS neurones having axons terminating outside the blood-brain barrier. Brain Res 505:171-175.

Anderson CR, Edwards SL (1994) Intraperitoneal injections of fluorogold reliably labels all sympathetic preganglionic neurons in the rat. J Neurosci Methods 53:137-141.

Barraco RA, Martens KA, Parizon M, Normile HJ (1993) Adenosine A2a receptors in the nucleus accumbens mediate locomotor depression. Brain Res Bull 31:397-404.

Blum D, Hourez R, Galas MC, Popoli P, Schiffmann SN (2003) Adenosine receptors and Huntington's disease: implications for pathogenesis and therapeutics. Lancet Neurol 2:366-374.

Brooke RE, Pyner S, McLeish P, Buchan S, Deuchars J, Deuchars SA (2002) Spinal cord interneurones labelled transneuronally from the adrenal gland by a GFP-herpes virus construct contain the potassium channel subunit Kv3.1b. Auton Neurosci 98:45-50.

Chau D, Johns DG, Schramm LP (2000) Ongoing and stimulus-evoked activity of sympathetically correlated neurons in the intermediate zone and dorsal horn of acutely spinalized rats. J Neurophysiol 83:2699-2707.

Choca JI, Proudfit HK, Green RD (1987) Identification of A1 and A2 adenosine receptors in the rat spinal cord. J Pharmacol Exp Ther 242:905-910.

Choca JI, Green RD, Proudfit HK (1988) Adenosine A1 and A2 receptors of the substantia gelatinosa are located predominantly on intrinsic neurons: an autoradiography study. J Pharmacol Exp Ther 247:757-764.

Correia-de-Sa P, Ribeiro JA (1994a) Potentiation by tonic A2a-adenosine receptor activation of CGRP-facilitated $[3 \mathrm{H}]$-ACh release from rat motor nerve endings. Br J Pharmacol 111:582-588.

Correia-de-Sa P, Ribeiro JA (1994b) Tonic adenosine A2A receptor activation modulates nicotinic autoreceptor function at the rat neuromuscular junction. Eur J Pharmacol 271:349-355.

Correia-de-Sa P, Timoteo MA, Ribeiro JA (1996) Presynaptic A1 inhibitory/A2A facilitatory adenosine receptor activation balance depends on motor nerve stimulation paradigm at the rat hemidiaphragm. J Neurophysiol 76:3910-3919.

Cunha RA, Ribeiro JA (2000) Purinergic modulation of [(3)H]GABA release from rat hippocampal nerve terminals. Neuropharmacology 39:1156-1167.

Cunha RA, Milusheva E, Vizi ES, Ribeiro JA, Sebastiao AM (1994) Excitatory and inhibitory effects of $\mathrm{A} 1$ and $\mathrm{A} 2 \mathrm{~A}$ adenosine receptor activation on the electrically evoked $[3 \mathrm{H}]$ acetylcholine release from different areas of the rat hippocampus. J Neurochem 63:207-214.

Cunha RA, Correia-de-Sa P, Sebastiao AM, Ribeiro JA (1996) Preferential activation of excitatory adenosine receptors at rat hippocampal and neuromuscular synapses by adenosine formed from released adenine nucleotides. Br J Pharmacol 119:253-260.

Daly JW, Butts-Lamb P, Padgett W (1983) Subclasses of adenosine receptors in the central nervous system: interaction with caffeine and related methylxanthines. Cell Mol Neurobiol 3:69-80.

Dembowsky K, Czachurski J, Seller H (1985) An intracellular study of the synaptic input to sympathetic preganglionic neurones of the third thoracic segment of the cat. J Auton Nerv Syst 13:201-244.

Deuchars SA, Morrison SF, Gilbey MP (1995) Medullary-evoked EPSPs in neonatal rat sympathetic preganglionic neurones in vitro. J Physiol (Lond) 487:453-463.

Deuchars SA, Spyer KM, Gilbey MP (1997) Stimulation within the rostral ventrolateral medulla can evoke monosynaptic GABAergic IPSPs in sympathetic preganglionic neurons in vitro. J Neurophysiol 77:229-235.

Deuchars SA, Brooke RE, Frater B, Deuchars J (2001a) Properties of interneurones in the intermediolateral cell column of the rat spinal cord: role of the potassium channel subunit Kv3.1. Neuroscience 106:433-446.

Deuchars SA, Brooke RE, Deuchars J (2001b) Adenosine A1 receptors reduce release from excitatory but not inhibitory synaptic inputs onto lateral horn neurons. J Neurosci 21:6308-6320.

Deuchars SA, Atkinson L, Brooke RE, Musa H, Milligan CJ, Batten TF, Buckley NJ, Parson SH, Deuchars J (2001c) Neuronal P2X7 receptors are targeted to presynaptic terminals in the central and peripheral nervous systems. J Neurosci 21:7143-7152.

Ferre S, Fredholm BB, Morelli M, Popoli P, Fuxe K (1997) Adenosinedopamine receptor-receptor interactions as an integrative mechanism in the basal ganglia. Trends Neurosci 20:482-487.

Fowler JC (1989) Adenosine antagonists delay hypoxia-induced depression of neuronal activity in hippocampal brain slice. Brain Res 490:378-384.

Hara H, Sukamoto T, Kogure K (1993) Mechanism and pathogenesis of ischemia-induced neuronal damage. Prog Neurobiol 40:645-670.

Jarvis MF, Williams M (1989) Direct autoradiographic localization of adenosine A2 receptors in the rat brain using the A2-selective agonist, [3H]CGS 21680. Eur J Pharmacol 168:243-246.

Jones PA, Smith RA, Stone TW (1998) Protection against kainate-induced excitotoxicity by adenosine A2A receptor agonists and antagonists. Neuroscience 85:229-237.

Joshi S, Levatte MA, Dekaban GA, Weaver LC (1995) Identification of spinal interneurons antecedent to adrenal sympathetic preganglionic neurons using trans-synaptic transport of herpes simplex virus type 1 . Neuroscience 65:893-903.

Kaelin-Lang A, Lauterburg T, Burgunder JM (1999) Expression of adenosine A2a receptors gene in the olfactory bulb and spinal cord of rat and mouse. Neurosci Lett 261:189-191.

Katchman AN, Hershkowitz N (1993) Adenosine antagonists prevent hypoxia-induced depression of excitatory but not inhibitory synaptic currents. Neurosci Lett 159:123-126.

Kirk IP, Richardson PJ (1995) Inhibition of striatal GABA release by the adenosine A2a receptor is not mediated by increases in cyclic AMP. J Neurochem 64:2801-2809.

Koh HC, Shin IC, Hwang SJ, Paik DJ (1996) Modification of cardiovascular response of adenosine A1 receptor agonist by cyclic AMP in the spinal cord of the rats. Neurosci Lett 219:195-198.

Koh HC, Lee TK, Kang JS, Lee CH, Lee H, Paik DJ, Shin IC (2000) Modification of cardiovascular response of adenosine A2 receptor agonist by adenylate cyclase in the spinal cord of rats. Neurosci Lett 293:45-48.

Kurokawa M, Kirk IP, Kirkpatrick KA, Kase H, Richardson PJ (1994) Inhibition by KF17837 of adenosine A2A receptor-mediated modulation of striatal GABA and ACh release. Br J Pharmacol 113:43-48.

Li H, Henry JL (1998) Adenosine A2 receptor mediation of pre- and postsynaptic excitatory effects of adenosine in rat hippocampus in vitro. Eur J Pharmacol 347:173-182.

Lopes LV, Cunha RA, Ribeiro JA (1999a) ZM 241385, an adenosine A(2A) receptor antagonist, inhibits hippocampal A(1) receptor responses. Eur J Pharmacol 383:395-398.

Lopes LV, Cunha RA, Ribeiro JA (1999b) Cross talk between A(1) and $\mathrm{A}(2 \mathrm{~A})$ adenosine receptors in the hippocampus and cortex of young adult and old rats. J Neurophysiol 82:3196-3203.

Lynge J, Hellsten Y (2000) Distribution of adenosine A1, A2A and A2B receptors in human skeletal muscle. Acta Physiol Scand 169:283-290.

Mayfield RD, Suzuki F, Zahniser NR (1993) Adenosine A2a receptor modulation of electrically evoked endogenous GABA release from slices of rat globus pallidus. J Neurochem 60:2334-2337.

Mori A, Shindou T, Ichimura M, Nonaka H, Kase H (1996) The role of adenosine A2a receptors in regulating GABAergic synaptic transmission in striatal medium spiny neurons. J Neurosci 16:605-611.

Ongini E, Adami M, Ferri C, Bertorelli R (1997) Adenosine A2A receptors and neuroprotection. Ann NY Acad Sci 825:30-48.

Parkinson FE, Fredholm BB (1990) Autoradiographic evidence for 
G-protein coupled A2-receptors in rat neostriatum using [3H]-CGS 21680 as a ligand. Naunyn Schmiedebergs Arch Pharmacol 342:85-89.

Patel MK, Pinnock RD, Lee K (2001) Adenosine exerts multiple effects in dorsal horn neurones of the adult rat spinal cord. Brain Res 920:19-26.

Pedata F, Corsi C, Melani A, Bordoni F, Latini S (2001) Adenosine extracellular brain concentrations and role of A2A receptors in ischemia. Ann NY Acad Sci 939:74-84.

Poucher SM, Keddie JR, Singh P, Stoggall SM, Caulkett PW, Jones G, Coll MG (1995) The in vitro pharmacology of ZM 241385, a potent, non-xanthine A2a selective adenosine receptor antagonist. $\mathrm{Br} \mathrm{J}$ Pharmacol 115:1096-1102.

Rebola N, Oliveira CR, Cunha RA (2002) Transducing system operated by adenosine $\mathrm{A}(2 \mathrm{~A})$ receptors to facilitate acetylcholine release in the rat hippocampus. Eur J Pharmacol 454:31-38.

Rosin DL, Robeva A, Woodard RL, Guyenet PG, Linden J (1998) Immunohistochemical localization of adenosine A2A receptors in the rat central nervous system. J Comp Neurol 401:163-186.

Schramm LP, Livingstone RH (1987) Inhibition of renal nerve sympathetic activity by spinal stimulation in rat. Am J Physiol 252:R514-R525.

Schroder UH, Opitz T, Jager T, Sabelhaus CF, Breder J, Reymann KG (1999) Protective effect of group I metabotropic glutamate receptor activation against hypoxic/hypoglycemic injury in rat hippocampal slices: timing and involvement of protein kinase C. Neuropharmacology 38:209-216.

Sebastiao AM, Ribeiro JA (1996) Adenosine A2 receptor-mediated excitatory actions on the nervous system. Prog Neurobiol 48:167-189.

Shen E, Mo N, Dun NJ (1990) APV-sensitive dorsal root afferent transmis- sion to neonate rat sympathetic preganglionic neurons in vitro. J Neurophysiol 64:991-999.

Shindou T, Mori A, Kase H, Ichimura M (2001) Adenosine A(2A) receptor enhances GABA(A)-mediated IPSCs in the rat globus pallidus. J Physiol (Lond) 532:423-434

Shindou T, Nonaka H, Richardson PJ, Mori A, Kase H, Ichimura M (2002) Presynaptic adenosine A2A receptors enhance GABAergic synaptic transmission via a cyclic AMP dependent mechanism in the rat globus pallidus. Br J Pharmacol 136:296-302.

Simpson RE, O'Regan MH, Perkins LM, Phillis JW (1992) Excitatory transmitter amino acid release from the ischemic rat cerebral cortex: effects of adenosine receptor agonists and antagonists. J Neurochem 58:1683-1690.

St. Lambert JH, Thomas T, Burnstock G, Spyer KM (1997) A source of adenosine involved in cardiovascular responses to defense area stimulation. Am J Physiol 272:R195-R200.

Strack AM, Sawyer WB, Platt KB, Loewy AD (1989) CNS cell groups regulating the sympathetic outflow to adrenal gland as revealed by transneuronal cell body labeling with pseudorabies virus. Brain Res 491:274-296.

Sweeney MI (1997) Neuroprotective effects of adenosine in cerebral ischemia: window of opportunity. Neurosci Biobehav Rev 21:207-217.

Umemiya M, Berger AJ (1994) Activation of adenosine A1 and A2 receptors differentially modulates calcium channels and glycinergic synaptic transmission in rat brainstem. Neuron 13:1439-1446.

Winder DG, Conn PJ (1993) Activation of metabotropic glutamate receptors increases cAMP accumulation in hippocampus by potentiating responses to endogenous adenosine. J Neurosci 13:38-44. 